\title{
LA FORMACIÓN COMO HERRAMIENTA DE PREVENCIÓN DE RIESGOS LABORALES EN ENFERMERÍA
}

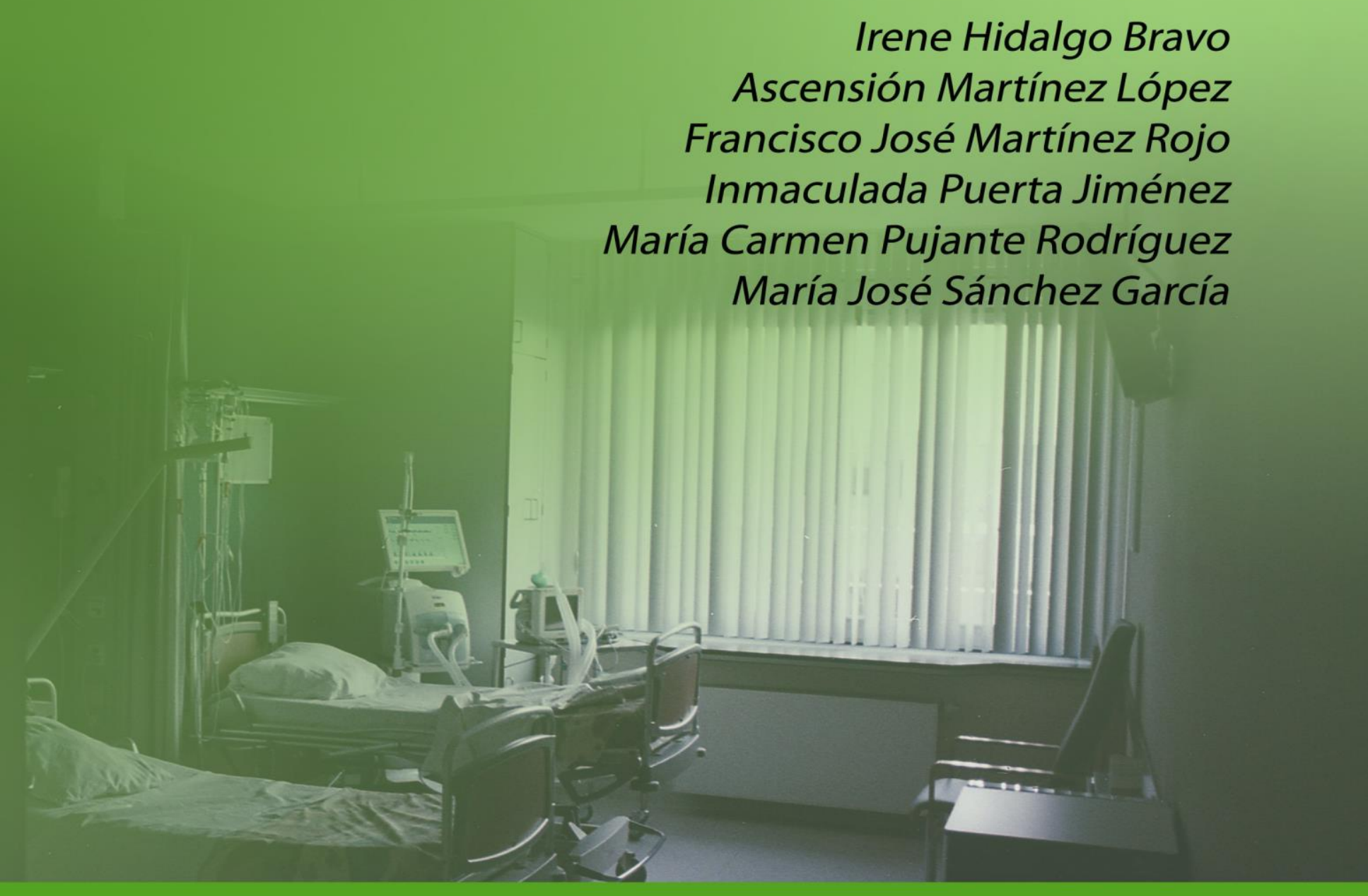

Medicina y Salud 



\section{LA FORMACIÓN COMO HERRAMIENTA DE PREVENCIÓN DE RIESGOS LABORALES EN ENFERMERÍA}

Autores:

Irene Hidalgo Bravo

Ascensión Martínez López

Francisco José Martínez Rojo

Inmaculada Puerta Jiménez

María Carmen Pujante Rodríguez

María José Sánchez García 


\section{${ }^{3}$ ciencias}

Editorial Área de Innovación y Desarrollo,S.L.

Q comunicada públicamente o utilizada, total o parcialmente, sin previa autorización.

(c) del texto: Los autores

ÁREA DE INNOVACIÓN Y DESARROLLO, S.L.

C/ Els Alzamora, 17 - 03802 - ALCOY (ALICANTE) info@3ciencias.com

Primera edición: 1 de octubre de 2017

ISBN: 978-84-947848-9-7

DOI: http://dx.doi.org/10.17993/Med.2017.48 


\section{Índice}

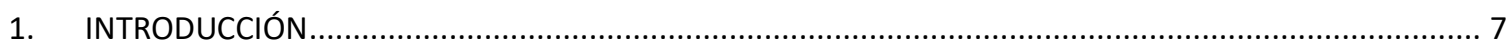

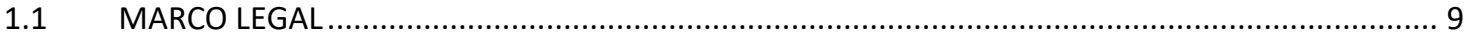

1.2 ¿Cómo podemos adaptar la formación a las necesidades del personal sanitario? ....................... 10

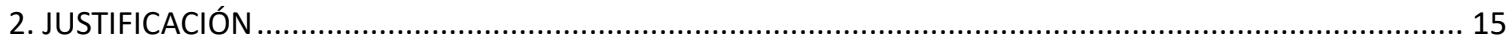

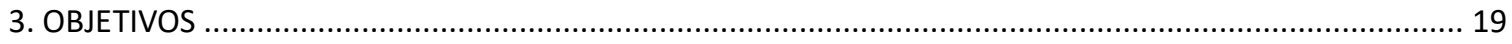

4. RIESGOS LABORALES ASOCIADOS A LA PROFESIÓN DE ENFERMERÍA ................................................. 21

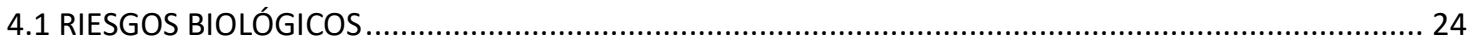

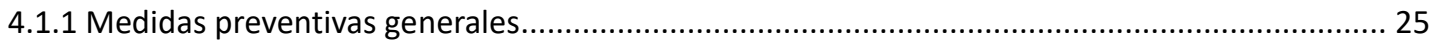

4.1.2 ¿Qué debemos saber? (a desarrollar en el plan de formación) .................................................... 26

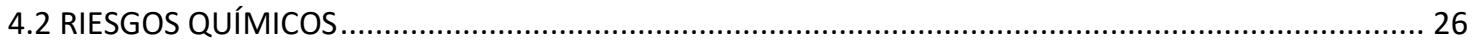

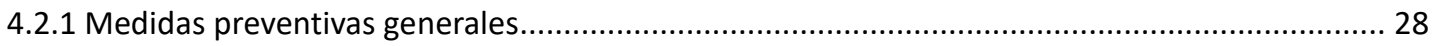

4.2.2 ¿Qué debemos saber? (a desarrollar en el plan de formación) .................................................. 28

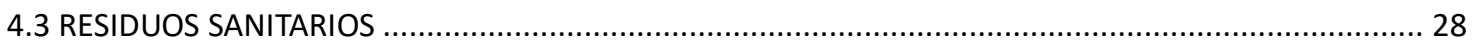

4.3.1 ¿Qué debemos saber? (a desarrollar en el plan de formación) ..................................................... 30

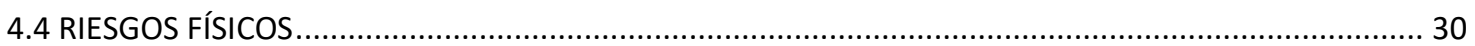

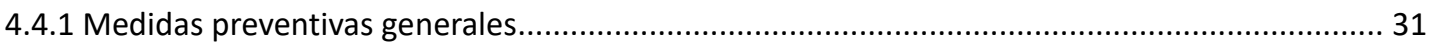

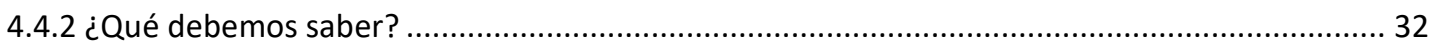

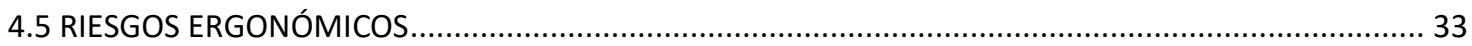

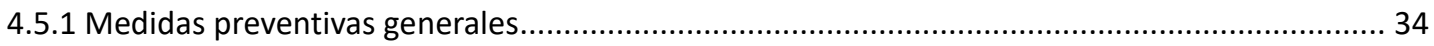

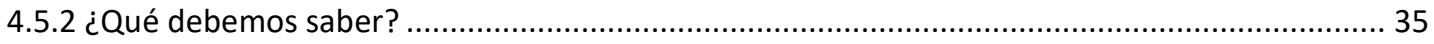

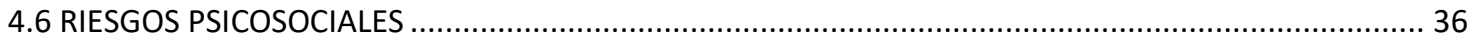

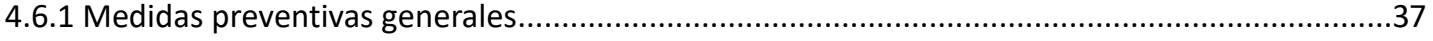

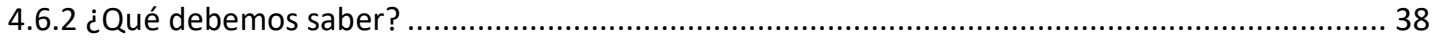

5. COMUNICACIÓN Y FORMACIÓN EN PREVENCIÓN DE RIESGOS LABORALES ............................................ 39

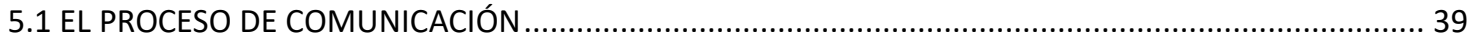

5.1.1 Comunicación por parte de la empresa hacia el trabajador ........................................................... 39

5.1.2 Comunicación por parte del trabajador hacia la empresa ............................................................ 42

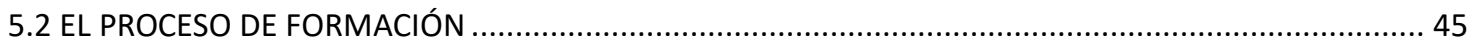

6. LA FORMACIÓN COMO HERRAMIENTA DE PREVENCIÓN EN ENFERMERÍA .......................................... 51

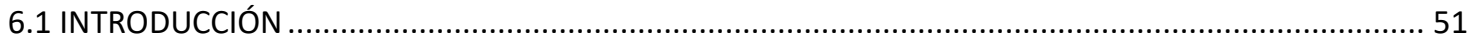

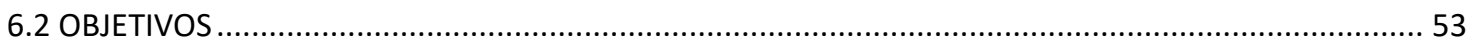




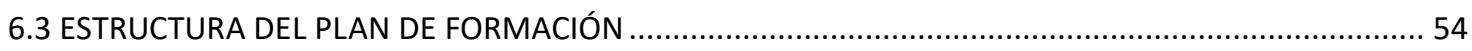

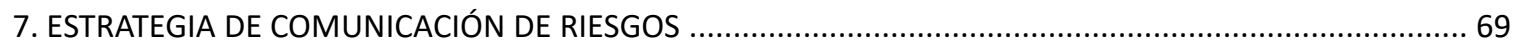

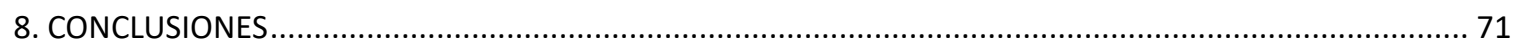

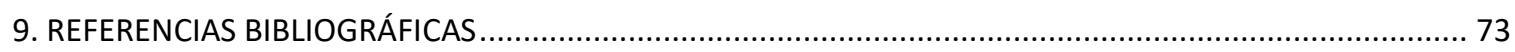

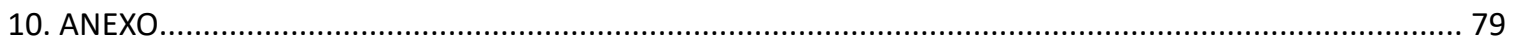




\section{INTRODUCCIÓN}

El sector sanitario constituye uno de los empleadores más importante del sector servicios, ocupando entre un 7 y un $13 \%$ de la mano de obra europea. Aunque históricamente se podría decir que el empleo sanitario ha sido ocupado mayoritariamente por personas licenciadas, siendo minoritaria la profesión de enfermería, actualmente esto no es así y podemos afirmar que se trata de un sector con una elevada jerarquización en el que encontramos diversas profesiones sanitarias, así como diferentes edades y sexos. De hecho, durante la década de los años 70 la profesión de enfermería sufrió un auge siendo representada de forma mayoritaria por mujeres (1).

El papel que juega la enfermería dentro del sector sanitario es muy importante, ya que se trata de un personal que está en contacto directo con el paciente, sano o enfermo, la mayor parte del tiempo de su jornada laboral. Este hecho hace necesario que en este colectivo exista una cierta actualización no solo en cuanto a conocimientos técnicos y científicos, sino también en relación a la prevención de riesgos laborales, ya que tanto la salud del paciente como la suya propia es responsabilidad de ellos. La gestión de riesgos es una metodología usada cada vez con mayor frecuencia en el sector sanitario, y su objetivo no es únicamente la salud del paciente, sino también la del propio trabajador (2).

La actual política de la Unión Europea en materia de salud y seguridad se centra en la creación de un entorno laboral seguro, es decir, promueve el "bienestar en el trabajo". Además, está comprobado que un entorno y una organización del trabajo sanos y seguros favorece el rendimiento y el beneficio económico de la empresa. El sector de la salud es uno de los sectores en los que se registra una mayor tasa de accidentabilidad laboral y para combatir este hecho es necesario conocer los cambios que se han producido en las últimas décadas tanto a nivel del trabajo que se realiza como en la sociedad que lo desempeña.

Los cambios detectados a nivel del trabajo incluyen, por ejemplo, factores como las nuevas formas de contratación, la temporalidad, los contratos a jornada parcial y los horarios atípicos. Es un hecho que estos factores afectan negativamente a la salud del trabajador, que sufre episodios de incertidumbre, inseguridad, constante adaptación a nuevas situaciones, cambios de jefes, compañeros, objetivos, etc. Pero si nos centramos en el tema que nos atañe en este trabajo y 
ponemos un ejemplo real que es muy fácil encontrar actualmente en el sector sanitario, también podemos comentar la dificultad que puede suponer para un trabajador sanitario que está contratado al $50 \%$ durante un mes, recibir la formación necesaria en cuanto a prevención de riesgos laborales. Si además añadimos que este sanitario cambia de servicio al mes siguiente, la posible formación que haya recibido en cuanto a prevención de riesgos a lo mejor no se adapta a las necesidades formativas necesarias para el nuevo desempeño de su trabajo. Tristemente, estas situaciones son más frecuentes de lo que deberían en la sanidad pública de nuestro país y hacen que sea mucho más necesario e importante tener en cuenta la formación en riesgos laborales para este colectivo.

Asociados a los cambios a nivel del trabajo podemos mencionar los cambios detectados en la naturaleza de los riesgos a los cuales se enfrentan los sanitarios. Estos riesgos hacen referencia a la naturaleza del trabajo, cambios en la organización, mayor carga mental y mayores exigencias individuales en el desempeño del trabajo, etc. Se trata de riesgos psicosociales que cada vez con mayor frecuencia producen enfermedades asociadas al estrés laboral, depresiones o ansiedad. Por otro lado, este tipo de riesgos influyen en el desarrollo del trabajo rutinario del sanitario, el cual, si está sometido a una gran carga de trabajo, ya sea física o mental, o sufre estrés laboral, seguramente cometerá errores que afecten a la prevención de riesgos químicos y biológicos. Por lo tanto, los tipos de riesgos presentes en las profesiones sanitarias están relacionados, y lo ideal sería formar a este colectivo en relación al conjunto de riesgos laborales a los que se enfrentan cada día.

Como se ha mencionado anteriormente, la política de la Unión Europea en cuanto a salud en el trabajo se centra en crear organizaciones y ambientes laborales saludables. Para ello, se plantean una serie de objetivos entre los cuales podemos mencionar la reducción en el número de accidentes y enfermedades profesionales, prevenir tanto los riesgos sociales como las enfermedades profesionales, tener en cuenta los cambios que se han producido en las formas de desarrollar el trabajo y en su organización y analizar los nuevos riesgos emergentes. En general podemos decir que se trata de reforzar la cultura de prevención, y para ello debemos centrarnos en la educación, la sensibilización y la anticipación o prevención (3). 


\subsection{MARCO LEGAL}

A nivel europeo, la Directiva Marco sobre salud y seguridad en el trabajo ${ }^{1}$, fue la que marcó un antes y un después en cuanto a la salud de los trabajadores. Aparece por primera vez el término "entorno de trabajo" y se hace referencia también por primera vez a la necesidad de gestionar adecuadamente la salud y seguridad de los trabajadores. Esta directiva fue adoptada en el año 1989 y garantiza unos requisitos mínimos en cuanto a salud y seguridad en el trabajo en toda Europa, permitiendo a su vez que los estados miembros puedan participar adaptando dicha directiva a sus necesidades.

En 1995 se aprobó en nuestro país la Ley de Prevención de Riesgos Laborales ${ }^{2}$ y en ella se hace referencia al derecho del trabajador en cuanto a "información, consulta, participación y formación en materia preventiva". El artículo 19 del capítulo III se centra en la formación de los trabajadores y en él podemos leer la obligación por parte del empresario de que los trabajadores tengan una correcta formación, tanto teórica como práctica, de los riesgos laborales asociados a su actividad laboral. Se especifica que esta formación debe realizarse en el momento de contratación del profesional (sea cual sea la modalidad o duración de esta), así como cuando el trabajador sufra cambios en las actividades que realiza o en las tecnologías con las que debe desempeñar su puesto. También se menciona en el artículo 19 que la formación que reciban los trabajadores debe ser impartida dentro de la jornada laboral de los mismos y sin coste alguno para el trabajador.

Este último punto suele cumplirse en la mayoría de las empresas, sin embargo, no podemos decir lo mismo del anterior, relacionado con el momento en el que se debe impartir la formación. Como hemos mencionado antes, las nuevas formas de trabajo en el sector sanitario incluyen tipos de contrato que hace unos años no eran frecuentes. Por ejemplo, contratos a media jornada durante un mes. La situación real en los servicios públicos es esta: cuando un trabajador sanitario, una enfermera, se incorpora a un puesto de trabajo en un hospital público, previa llamada de la bolsa de trabajo, ni siquiera sabe en qué servicio clínico va a desarrollar su

\footnotetext{
1 Directiva 89/391/CEE del Consejo, de 12 de junio de 1989, relativa a la aplicación de medidas para promover la mejora de la seguridad y de la salud de los trabajadores en el trabajo (Directiva Marco).

2 Ley 31/1995, de 8 de noviembre, de Prevención de Riesgos Laborales BOE no 269 10/11/1995.
} 
actividad laboral. Si además se trata de un contrato de verano, es fácil que cambie de servicio cada semana, según las necesidades que haya de personal en el hospital. No se puede generalizar, pero basándome en mi experiencia laboral, la formación en prevención de riesgos laborales en estos casos es insuficiente o nula, porque este tipo de formación suele estar dirigida a la plantilla fija de un hospital, no a las nuevas incorporaciones que se realizan, a veces cada mes, debido a la actual precariedad en los contratos laborales.

Por último mencionar el R.D. $843 / 2011^{3}$ por el cual se establecen los criterios básicos sobre la organización de recursos para desarrollar la actividad sanitaria de los servicios de prevención. Aunque el principal objetivo de estos servicios de prevención es la vigilancia para la salud, en el artículo 3 del R.D. 843/2011 se señala que entre sus obligaciones también se encuentran la de “impulsar programas de promoción de la salud en el lugar de trabajo, en coordinación con el Sistema Nacional de Salud" y "desarrollar programas de formación, información e investigación en su ámbito de trabajo".

\section{2 ¿Cómo podemos adaptar la formación a las necesidades del personal sanitario?}

Para implantar una cultura de prevención en el entorno laboral hay tres aspectos que debemos tenemos en cuenta. La educación, la sensibilización y la anticipación (4).

La educación en prevención de riesgos no debe iniciarse cuando el trabajador se incorpora al mundo laboral, sino que debe iniciarse antes. En nuestro caso, el colectivo de enfermería debe comenzar su educación en prevención de riesgos durante la carrera universitaria. Se le debe dar una importancia plena a la adquisición de estos conocimientos, sobre todo teóricos, para que los alumnos sean capaces de ponerlos en práctica cuando tengan su primer contacto con el mundo laboral, que además será durante sus años universitarios con el desarrollo de las prácticas en hospitales. También es necesario incidir en que esta formación debe ser continua, ya que el cambio que se produce en los riesgos laborales también lo es. Por lo tanto, estos conocimientos previos adquiridos durante los años de estudiantes deben ser reforzados a lo largo de su carrera profesional y esto es responsabilidad de la empresa.

\footnotetext{
${ }^{3}$ Real Decreto 843/2011, de 17 de junio, por el que se establecen los criterios básicos sobre la organización de recursos para desarrollar la actividad sanitaria de los servicios de prevención.
} 
La sensibilidad es necesaria para que los trabajadores sean conscientes de los riesgos a los que están expuestos y del peligro que corren si no toman las medidas preventivas correctas para enfrentarse a ellos. Hay que informar a los trabajadores porque el desconocimiento o la ignorancia conllevan al error.

Y por último, la anticipación a los riesgos, ya sean conocidos o riesgos emergentes, nos ayuda a controlarlos. Es necesario conocer el entorno laboral de este colectivo, es decir, saber con qué productos o tecnologías trabaja, cómo se desarrolla su trabajo, que horarios, turnos o rotaciones por distintos servicios clínicos hacen, etc. Es decir, la persona que se va a hacer cargo de la formación debe estar informada de todo lo mencionado para conseguir que la formación sea lo más específica posible a las necesidades de los alumnos.

Según el artículo 19 de la Ley de Prevención de Riesgos Laborales, la formación en este sentido debe cumplir ciertos requisitos (5).

- Debe ser una formación teórica y práctica. No sólo deben conocerse los riesgos a los que el trabajador se expone, sino que se debe preparar al trabajador para prevenirlos $y$ enfrentarse a ellos, así como sobre las medidas que se deben tomar en caso de que estos dos primeros pasos fracasen. Los ejemplos prácticos siempre ayudan al alumno a ponerse en situación, por lo que la formación práctica es necesaria en prevención de riesgos.

- Debe ser una formación adecuada y suficiente. Este punto está relacionado con lo comentado sobre la necesidad de conocer el puesto de trabajo que desarrollan estos profesionales. De esta forma se podrá ofrecer una formación adecuada a su puesto de trabajo y suficiente para que sean capaces de desarrollarlo sin ningún perjuicio para su salud.

- Debe ser, lógicamente, una formación centrada en materia preventiva. No se trata de hacer una formación general sobre su puesto de trabajo o sobre cómo desarrollar su actividad laboral, sino de formar al profesional para que desarrolle su trabajo en un ambiente saludable y de la forma más segura posible. Que conozca los recursos que para ello tiene a su alcance y enseñarlos a hacer uso de ellos.

- Deber ser una formación periódica y adaptada: ya se ha hablado de la necesidad de la periodicidad en cuanto a la formación en prevención de riesgos. Esta necesidad es 
importante porque ayuda a que sensibilicemos a los trabajadores sobre la existencia de los riesgos laborales. No se trata de hacer un curso de formación anual y olvidarnos de él, sino de intentar incluir la formación en el desarrollo de trabajo, que el trabajador no lo vea como algo "que hay que hacer", sino conseguir que quiera hacerlo y cuanto más adaptemos esta formación a la evolución del trabajo desarrollado, a su complejidad, al manejo de nuevas tecnologías, etc., más involucrado se verá el trabajador y más útil le resultará esta formación.

- Finalmente, esta formación debe ser gratuita. Es obligación del empresario formar a los trabajadores en relación a la prevención de riesgos laborales, por lo tanto, los costes de la misma correrán a cargo de la empresa.

En cuanto a la modalidad de la formación, esta puede ser presencial o puede ser online. Las ventajas y desventajas de ambas modalidades nos deben hacer definirnos por un tipo de formación u otra, aunque seguramente lo ideal es una combinación de ambas, de manera que la formación online nos permita resaltar el carácter periódico de la formación en prevención de riesgos laborales, y la formación presencial nos permita desarrollar las actividades prácticas que deben incluirse en la misma.

Además de todo esto, es necesario mencionar que una buena comunicación es imprescindible para que el desarrollo de la formación sea completo y efectivo. Y por supuesto, la comunicación deber ser recíproca, es decir, de la empresa hacia el trabajador y del trabajador hacia la empresa ya que, tan importante es que la empresa comunique al trabajador los riesgos a los que se expone en su día a día como que, el trabajador comunique a la empresa los riesgos que detecta en su trabajo diario.

A la hora de elaborar un plan de formación dirigido a la formación en prevención de riesgos laborales tendremos que tener en cuenta varios puntos, de hecho, el diseño de un plan de formación consta de varias etapas (6):

- Conocer la empresa a la que va dirigido el plan de formación

- Identificar las necesidades formativas de la misma

- Diseñar un plan de formación acorde a esas necesidades

- Llevar a cabo el plan de formación 
- Evaluar el plan de formación para ver si se han cumplido los objetivos

- Llevar a cabo las acciones de mejora necesarias en base al punto anterior

En este trabajo nos centraremos en las tres primeras etapas, sin olvidar que lo correcto sería ejecutar el plan de formación que diseñemos, evaluarlo y mejorarlo cuando sea necesario.

Como ya se ha comentado, el plan de formación que se pretende realizar en este trabajo va dirigido a un colectivo dentro de las profesiones sanitarias, la enfermería. Por lo tanto, se puede decir que el plan de formación irá dirigido a los centros sanitarios en general ya sean ambulatorios, hospitales o clínicas privadas.

En cuanto a las necesidades formativas en materia de prevención de riesgos laborales se hará uso de la VII Encuesta Nacional de Condiciones de Trabajo, en la que se puede encontrar las deficiencias que los profesionales sanitarios detectan en relación a los riesgos que perciben en su trabajo y su capacidad para prevenirlos. Para completar este apartado se tendrá en cuenta la opinión de los estudiantes de prácticas de enfermería que cada año rotan por los diferentes centros sanitarios mencionados. Los alumnos de prácticas son importantes porque se trata de personas formadas en prevención de riesgos mediante sus estudios universitarios, pero que por primera vez se van a enfrentar a las tareas prácticas propias de su profesión. Por lo tanto, estas personas no están acostumbradas a trabajar mal, es decir, ellos van a percibir el riesgo desde el primer momento que tengan que realizar una tarea sin las medidas preventivas oportunas. Ya sabemos, que cuando una persona lleva años realizando una tarea, al final no es capaz de detectar el riesgo que esta tarea conlleva o incluso lo detecta, y por confianza lo asume sin tomar medidas respecto a él. Una persona que está empezando su trayectoria laboral, como un estudiante de prácticas, es ideal como fuente de información de los riesgos que percibe durante su horario laboral, por eso es importante establecer estrategias de comunicación que les permitan transmitir los riesgos que perciben, las medidas preventivas que no detectan en el trabajo de sus compañeros o la falta de disponibilidad de recursos que permitan adoptar correctamente las medidas preventivas necesarias para desarrollar una tarea. Por lo tanto, a partir de esta información se podrá detectar también deficiencias e incorporarlas al plan de formación, que va dirigido a todo el personal de enfermería, no sólo a los estudiantes. 
Y teniendo en cuenta estas necesidades, se realizará un plan de formación dirigido a mejorar los conocimientos en materia de prevención de riesgos laborales en el colectivo de enfermería, intentando combinar tanto la formación online como la formación presencial.

Finalmente, hacer hincapié en la necesidad de completar el diseño del plan de formación con las tres últimas etapas de las que consta un plan de formación: la ejecución, la evaluación y la mejora del mismo, en caso necesario. 


\section{JUSTIFICACIÓN}

La profesión de enfermería, así como el resto de profesiones sanitarias, se enfrenta diariamente a muchos riesgos laborales, por lo que la capacidad de estos profesionales para prevenir dichos riesgos, detectarlos y afrontarlos correctamente es primordial para mantener la salud de los trabajadores y de la organización en sí.

Entre los principales riesgos laborales que afectan a estos profesionales podemos destacar:

- Riesgos químicos y biológicos: durante su rutina laboral diaria los trabajadores entran en contacto con diversas sustancias (muestras biológicas, desinfectantes, medicamentos), objetos sanitarios peligrosos, pacientes potencialmente infecciosos, etc., que ponen en riesgo su salud si no saben manejar estas situaciones correctamente.

- Riesgos físicos: dependiendo del servicio clínico en el que los profesionales desempeñen su trabajo estarán más o menos expuestos a radiaciones, ya sean ionizantes o no ionizantes. Por lo tanto, se les debe informar sobre este aspecto, ya que aunque en un determinado momento no estén expuestos a este tipo de riesgos, por las rotaciones de servicios que suelen realizar los profesionales de enfermería, en algún momento podrían estarlo.

- Riesgos ergonómicos: las diversas posturas laborales, ya sea en el manejo de pacientes, como de monitores o de ordenadores y mesas de trabajo, son también una fuente de riesgos que se deben tener en cuenta, aunque para la mayoría de los trabajadores, ya sea por ignorancia o por confianza, no suelen tratarse de riesgos reales.

- Riesgos psicosociales: los riesgos psicosociales, desconocidos por muchos trabajadores sanitarios, son muy importantes y están muy presentes en las profesiones sanitarias, sobre todo en la enfermería, ya que por las características adheridas a esta profesión son riesgos reales a los que se enfrentan los sanitarios. Podemos mencionar algunos de ellos como por ejemplo la nocturnidad, los turnos rotatorios, los equipos volantes, la falta de rol, la carga emocional o mental, la dificultad para conciliar vida laboral y personal, etc. Todas estas situaciones pueden afectar al personal sanitario generando estrés laboral, una de las más frecuentes causas de bajas laborales en el sector. 
Si analizamos la VII Encuesta Nacional de Condiciones de Trabajo (7) los datos generales que obtenemos son que un $69 \%$ de trabajadores percibe riesgo de accidentarse en su trabajo y que la exposición a agentes químicos y biológicos está presente en un $23 \%$ y un $7 \%$, respectivamente. Un $84 \%$ de los trabajadores afirma tener molestias que se deben a posturas o condiciones físicas de su trabajo, y finalmente, en cuanto a los factores psicosociales del trabajo, estos han empeorado respecto a los resultados de la VI Encuesta Nacional de Condiciones de Trabajo.

Si nos centramos en las profesiones sanitarias, observamos que éstas se encuentran dentro del grupo de trabajadores más afectados por la manipulación $(31,4 \%)$, inhalación $(13,4 \%)$ y exposición $(34,0 \%)$ a agentes químicos. Sin embargo es una de las profesiones en las que el desconocimiento de los efectos perjudiciales de dichos agentes químicos es menos frecuente, representando sólo un 10,3\%. Pero lo importante no es sólo conocer los efectos perjudiciales de la manipulación de sustancias tóxicas, sino utilizar las medidas preventivas correctas para evitar riesgos. $Y$ en este caso nos encontramos que un $8,8 \%$ de los profesionales sanitarios no sabe qué debe hacer en estas situaciones. En cuanto a la manipulación de agentes biológicos, el grupo profesional que en mayor medida indica estar expuestos a ellos son los trabajadores sanitarios (47\%).

En referencia a los riesgos ergonómicos, como ya se ha comentado anteriormente, el personal sanitario realiza diversas actividades que afectan a su salud a largo plazo. Estas actividades, de mayor a menor frecuencia de realización, son: repetir los mismos movimientos de manos y brazos $(54,3 \%)$, adoptar posturas dolorosas o fatigantes $(50,3 \%)$, levantar o mover personas $(43,9 \%)$, estar de pie sin andar $(37,1 \%)$, aplicar fuerzas importantes $(28,1 \%)$ y estar sentados sin levantarse (18,5\%). Las consecuencias de estas actividades son las molestias musculoesqueléticas, que según la zona afectada oscilan desde un 50,9\% que afirma tener molestias en la zona baja de la espalda, hasta un 12,3\% que afirma tenerlas en brazos y antebrazos. Sólo un 18,0\% afirma no presentar ningún tipo de molestias. El diseño del puesto de trabajo también es un factor importante relacionado con los riesgos ergonómicos, y en este caso, sólo un $15,1 \%$ del personal sanitario se queja de tener poco espacio de trabajo.

Finalmente, en relación a los riesgos psicosociales, el personal sanitario es uno de los colectivos que indica que debe realizar con frecuencia tareas complejas. También es uno de los colectivos que se encuentra expuesto con mayor frecuencia a agresiones verbales, rumores o aislamiento 
social. El trabajo nocturno o rotario también es frecuente en las profesiones sanitarias $(23,8 \%)$, y el trabajo en días festivos así como las prolongaciones de jornadas representa un 35,9\% en este sector.

En cuanto a la exposición de riesgos en su trabajo diario, el personal sanitario percibe riesgos en el desarrollo de su trabajo diario (81,9\%).

A toda esta información facilitada por la VII Encuesta Nacional de Condiciones de Trabajo podemos añadir la obtenida del informe anual de accidentes de trabajo en España del Observatorio Estatal de Condiciones de Trabajo (8), según el cual, los accidentes laborales asociados a las profesiones sanitarias en nuestro país fueron de 2.417 en el año 2014 y de 2.463 en el año 2015, representando un aumento de un 1,9\%.

Este aumento en el número de accidentes laborales sanitarios unido a las percepciones de riesgos valoradas por el personal sanitario en la encuesta mencionada anteriormente, nos podría indicar que la prevención de riesgos laborales en este sector es un tema que todavía queda por perfeccionar y que es necesario insistir en la formación en materia de prevención de riesgos en estos profesionales.

Esta es una de las razones por las que ha surgido realizar este trabajo, un plan de formación en prevención de riesgos laborales orientado a la profesión de enfermería.

Actualmente, en la mayoría de hospitales se trabaja bajo una presión elevada, debida sobre todo a la falta de recursos, ya sean humanos como materiales, y este hecho hace que a veces no se piense en los riesgos que conlleva la labor de enfermería. Además, los planes de estudios universitarios facilitan la incorporación de alumnos de prácticas que trabajan diariamente con estos profesionales, y por lo tanto es necesario que ya durante su periodo de prácticas estos alumnos adquieran las herramientas necesarias para conocer los riesgos asociados a su profesión y las medidas preventivas para evitarlos 


\section{OBJETIVOS}

El principal objetivo de este trabajo es elaborar un plan de formación orientado a la prevención de riesgos laborales en la profesión de enfermería. Como objetivos secundarios que nos ayudarán a la elaboración de dicho plan de formación, nos planteamos:

- Describir los principales riesgos laborales (higiénicos, ergonómicos y psicosociales) que afectan a la profesión de enfermería, así como las principales medidas preventivas que hay que adoptar en estos casos.

- Desarrollar un plan de formación de acuerdo a las necesidades formativas de este colectivo de profesionales, con la finalidad de que se pueda ejecutar en un futuro.

- Establecer una estrategia de comunicación que permita a los profesionales informar de los riesgos detectados durante el desarrollo de su trabajo. 
La formación como herramienta de prevención de riesgos laborales en enfermería 


\section{RIESGOS LABORALES ASOCIADOS A LA PROFESIÓN DE ENFERMERÍA}

El sector sanitario es uno de los sectores laborales en el cual podemos encontrar la totalidad de los riesgos laborales, ya sean, riesgos biológicos, físicos, ergonómicos o psicosociales. Esto es debido a que se trata de un sector en el que confluyen diferentes especialidades (médicos, enfermeros, auxiliares, celadores, administrativos, etc.) y diferentes tipos de trabajo.

La presencia de estos riesgos puede dar lugar a que se produzcan accidentes de trabajo, debidos por ejemplo a caídas, golpes, incendios, contactos eléctricos, agresiones, sobreesfuerzos, pinchazos accidentales, etc.; también pueden causar enfermedades profesionales si existe sobreexposición a ruidos, vibraciones, agentes biológicos o químicos peligrosos, etc.; y por último, también pueden aparecer enfermedades relacionadas con el trabajo, en este caso sobre todo, a los peligros de origen ergonómico y psicosocial. Este último apunte es importante porque debemos tener en cuenta que los actuales cambios que se están sufriendo a nivel del trabajo también están afectando a las profesiones sanitarias. Estos cambios son principalmente los referidos a las jornadas de trabajo, la organización del mismo, la turnicidad, los tipos de contratos que se están ofertando (tiempo parcial), etc., y son cambios que a su vez generan factores de riesgo psicosocial sobre los cuales hay que prevenir a estos profesionales con la misma intensidad con la que lo hacemos respectos a los riesgos higiénicos o ergonómicos (9).

Analizando el informe anual sobre el estado de la seguridad y la salud laboral en España de 2015 (10) vemos que en los últimos tres años analizados (2011-2013) las principales causas de accidentes de trabajo están relacionadas con la organización del trabajo y la gestión preventiva, y que además, en 2015 se ha producido un importante aumento en el número de enfermedades causadas por el trabajo $(10,4 \%)$ respecto a 2014 . Dentro de las causas relacionadas con la organización del trabajo, la más frecuente es "método de trabajo inadecuado" y en cuanto a la gestión preventiva, se mencionan como más frecuentes dos causas: la "no identificación de riesgos" y la "no ejecución de las medidas preventivas propuestas en la planificación derivada de la evaluación de riesgos". A partir de estos datos podemos extraer la importancia que tiene la formación en los trabajadores, y cuando hablamos de formación nos referimos no sólo a la relativa a cómo realizar correctamente la tarea asignada, sino también a la formación en 
prevención de riesgos laborales para que sean capaces de realizar la tarea de forma saludable y no atentando contra su salud.

Por lo tanto, una de las formas de reducir los accidentes laborales en el sector sanitario en general, y en la profesión de enfermería en concreto, sería definir un plan de formación en el que se recojan los principales riesgos laborales a los que están expuestos, así como las principales medidas preventivas para que puedan evitarlos. A su vez, habría también que señalar la importancia de la necesidad de informar todos los posibles riesgos que estos profesionales encuentren durante la realización de su trabajo diario.

Basándonos en la monografía realizada por la Escuela Nacional de Medicina del Trabajo (11), la profesión de enfermería podemos dividirla en cuatro especialidades que serían: enfermería de atención primaria y consultas, enfermería de hospitalización, enfermería de bloque quirúrgico y enfermería de emergencias.

El primer grupo, enfermería de atención primaria, tiene como principal función atender a personas que, ya sea por la edad, por lesiones, enfermedades, trastornos físicos o mentales, lo necesitan. Dentro de sus principales tareas encontramos las referentes a la atención al paciente (consultas, curas, extracciones de sangre, realización de pruebas complementarias, etc.) y tareas administrativas (manejo de documentación, uso del teléfono y la visualización de pantallas de datos (VPD)). El trabajo que realizan se considera de tipo "no sedentario ligero" con manejo de cargas y posturas forzadas. En cuanto a la carga física se considera de grado bajo-medio y en cuanto a las aptitudes psicosociales se caracteriza por tener un nivel intermedio de autonomía y un buen nivel de relación con el resto de trabajadores por la dependencia existente entre estos a la hora de realizar el trabajo.

El grupo de enfermería de hospitalización es un grupo de enfermería especializada cuyas funciones son tratar, ayudar y atender apersonas que necesitan cuidados de enfermería en los ámbitos de salud mental, geriatría, salud familiar y comunitaria, salud en el trabajo y pediatría. Entre las principales tareas relacionadas con la atención al paciente encontramos la acogida del mismo (indirectamente hay trato con los familiares), realización de curas y extracciones de sangre y preparación y administración de medicación. En cuanto a las tareas administrativas, destacan el manejo de documentación, el registro informático de tareas y la VPD. El trabajo de 
este subgrupo se considera de tipo "no sedentario moderado-elevado" con manejo de cargas y posturas forzadas (sobre todo en la realización de curas y en la movilización de pacientes), se considera de grado medio en cuanto a la carga física y se le exige un nivel medio de autonomía y buena relación con el resto de compañeros para el correcto funcionamiento del trabajo en equipo.

La enfermería del bloque quirúrgico tiene tareas muy importantes que ayudan a mantener las condiciones de asepsia necesarias en este tipo de intervenciones. Se encargan de la seguridad del paciente, de la coordinación del equipo quirúrgico y de la relación entre éste y el resto de servicios hospitalarios (anatomía patológica, laboratorio, banco de sangre, etc.), las principales tareas en relación a la atención al paciente son su acogida en quirófano y el trato con los familiares, preparación del material quirúrgico y de la instrumentalización necesaria y administrar medicación. En cuanto a las tareas administrativas prevalecen el uso del teléfono, el manejo de documentación y la VPD. Este trabajo se considera de tipo "no sedentario", con bipedestación tanto estática como dinámica. El grado de exigencia psicofísica es variable en función de la tarea, pudiendo ser ligera, media o intensa. Este tipo de trabajo es intenso o mantenido de manos, brazos y de hombros e incluye la realización de posturas forzadas. Se caracteriza también por un nivel alto de autonomía y elevada exigencia psíquica.

Por último, el grupo de enfermería de emergencias incluye el cuidado de niños, adolescentes, adultos y ancianos que padecen problemas de salud, crónicos o agudos, de naturaleza somática o psíquica, ya sea en el medio hospitalario o en el medio extra-hospitalario. En cuanto a la atención al paciente, las principales tareas son la exploración, toma de constantes, preparación y administración de medicación, canalización de vías, colaboración policía y bomberos, etc. Las tareas administrativas que realizan son las descritas para el resto de grupos: uso del teléfono, manejo de documentación y VPD. Este tipo de trabajo también se considera de tipo "no sedentario" y el grado de exigencia psicofísica puede variar en función de la tarea realizada, oscilando entre ligera, media o intensa. Las posturas forzadas están presentes en el desarrollo de la tarea y se necesita un nivel elevado de autonomía y de exigencia psíquica.

Una vez descritos los cuatro grupos que encontramos dentro de la profesión de enfermería, observamos que los riesgos laborales que les afectan, en mayor o menor medida según el grupo, son prácticamente los mismos. Los riesgos biológicos y químicos están presentes en los cuatro 
grupos ya que en todos los casos existe contacto directo con los pacientes y con el manejo de medicación y material de curas, etc. Los riesgos físicos estarán más o menos presentes en función de la actividad específica que realice el trabajador, es decir, si trabaja en una unidad en la que esté expuesto a radiaciones, que es principal riesgo incluido dentro de este grupo. Los riesgos ergonómicos también podemos considerarlos presentes ya que en todos los grupos existe la realización de posturas forzadas o mantenidas en el tiempo, la movilización de pacientes y el manejo de ordenadores y PVD. Y en cuanto a los riesgos psicosociales, la exigencia de autonomía, las exigencias psíquicas necesarias para la realización de determinadas tareas, el trato con pacientes y familiares, las condiciones de urgencia o la coordinación de grupos de trabajo, son potenciales factores de riesgo psicosocial que pueden derivar en la generación de estrés laboral si no se conocen las medidas preventivas necesarias para evitarlo.

\subsection{RIESGOS BIOLÓGICOS}

De todos los riesgos presentes en las profesiones sanitarias, el riesgo biológico es el más frecuente. Se considera riesgo biológico a la posibilidad de entrar en contacto con sangre o fluidos corporales y de sufrir inoculaciones accidentales al manipular objetos cortantes y punzantes, o exposiciones de piel y mucosas.

Las principales enfermedades a las que se ven expuestos los profesionales sanitarios en el ejercicio diario de su profesión son las de etiología vírica, sobre todo la Hepatitis B (VHB), la Hepatitis C (VHC) y el virus de la Inmunodeficiencia Humana Adquirida (VIH).

Por lo tanto, el riesgo biológico está relacionado con la exposición a los agentes biológicos, bacterias, virus, hongos, parásitos, etc. Y los fluidos biológicos que se consideran potencialmente peligrosos son todos aquellos implicados en la transmisión de este tipo de agentes infecciosos, es decir, la sangre, el suero, el plasma, cultivos de bacterias, de virus, sin olvidarnos de otros fluidos como los líquidos biológicos (cefalorraquídeo, sinovial, pleural, peritoneal, pericárdico y amniótico.

Podemos clasificar los agentes biológicos en cuatro grupos (12):

- Grupo 1: agentes con escasa probabilidad de causar una enfermedad en las personas. 
- Grupo 2: agentes que pueden causar una enfermedad en el ser humano y pueden suponer un peligro para quienes trabajan, siendo poco probable que se propaguen a la colectividad y existiendo generalmente profilaxis o tratamiento eficaz.

- Grupo 3: agentes que pueden causar una enfermedad grave en el ser humano y presentan un serio peligro para quienes trabajan, con riesgo de que se propaguen a la colectividad y existiendo generalmente una profilaxis o tratamiento eficaz.

- Grupo 4: agentes que causan una enfermedad grave en el ser humano y suponen un serio peligro para quienes trabajan, con muchas probabilidades de que se propaguen a la colectividad y sin que exista generalmente una profilaxis o tratamiento eficaz.

En cuanto a las vías de entrada, existen cinco vías:

- Vía respiratoria: el contagio se produce a partir de la inhalación de gotitas de Flügge y /o partículas de Wells, que quedan suspendidas en el ambiente cuando respiramos, hablamos, tosemos, siendo el vehículo de los gérmenes.

- Vía intradérmica: en este caso se necesita un vehículo que atraviese la piel y deposite en su interior los agentes infecciosos. Lo más común es que se trate de agujas, bisturís u otros objetos punzantes.

- Vía dérmica: en este caso el agente infeccioso se deposita sobre la piel y la atraviesa en aquellas situaciones en las cuales la barrera dérmica está alterada, como por ejemplo, heridas, fisuras, etc.

- Vía mucosa: el agente biológico alcanza zonas mucosas del organismo como la boca, los ojos. Al tratarse de zonas muy vascularizadas, su capacidad de absorción es máxima.

- Vía digestiva: cuando el agente biológico entra por vía oral al aparato digestivo, donde se absorberá.

\subsubsection{Medidas preventivas generales}

Las medidas preventivas que es necesario adoptar para prevenir los riesgos biológicos y que se conocen como precauciones universales son:

- La vacunación o inmunización activa

- Las normas de higiene personal

- Los elementos de protección barrera (EPIs) (guantes, mascarillas, batas) 
- El cuidado con objetos cortantes o punzantes

- La esterilización y desinfección de materiales y superficies

- La comunicación de los accidentes siguiendo el protocolo de actuación vigente

\subsection{2 ¿Qué debemos saber? (a desarrollar en el plan de formación)}

- Exposición accidental a un agente biológico. Ante una exposición accidental a un posible agente biológico, se debe seguir el protocolo existente para estos casos. En el plan de formación se debe incidir en la importancia de este protocolo para que todos los trabajadores lo conozcan y sepan cómo actuar en caso de necesidad.

- Proyecto EPINETAC. El proyecto EPINETAC es la versión española del proyecto EPINET desarrollado por la Universidad de Virginia en 1991. Se trata de un registro de accidentabilidad biológica a nivel mundial, para registrar con el mayor detalle posible el mecanismo de las exposiciones ocupacionales. En nuestro país existe el registro EPINETAC- Estudio y Seguimiento del Riesgo Biológico en el Personal Sanitario, que se inició en 1995, y que cada año son más los hospitales y centros sanitarios españoles que lo incorporan, aumentando de esta forma la representabilidad de los datos. Gracias a este registro se pueden planificar las estrategias de prevención y valorar la eficacia de los programas de intervención. En el plan de formación se presentará el proyecto EPINETAC para que los trabajadores conozcan sus principales objetivos y los resultados del mismo en los diferentes centros sanitarios españoles que lo conforman (13).

\subsection{RIESGOS QUÍMICOS}

Los riesgos químicos son importantes en las profesiones sanitarias ya que estos trabajadores manipulan sustancias químicas que pueden absorber, ya sea en forma de reactivos como de desinfectantes o medicamentos.

Según la Directiva 98/24/CE ${ }^{4}$ se define Agente Químico como "todo elemento o compuesto químico, por sí solo o mezclado, tal como se presenta en estado natural o es producido, utilizado o vertido, incluido el vertido como residuo, en una actividad laboral, se haya elaborado o no de

\footnotetext{
${ }^{4}$ Directiva 98/24/CE del Consejo de 7 de abril de 1998 relativa a la protección de la salud y la seguridad de los trabajadores contra los riesgos relacionados con los agentes químicos durante el trabajo (decimocuarta Directiva específica con arreglo al apartado 1 del artículo 16 de la Directiva 89/391/CEE).
} 
modo intencional y se haya comercializado o no". A su vez, definimos Agente Químico Peligroso como aquel que presenta un riesgo para la salud de los trabajadores debido a las propiedades físicoquímicas, químicas o toxicológicas que tiene, y a la forma en la que se utiliza o se halla presente en el lugar de trabajo (14).

Los compuestos químicos podemos clasificarlos como:

- Inflamables: cuando se eleva la temperatura pueden producir vapores y vienen definidos por su Punto de Inflamación (PI).

- Tóxicos: producen daño cuando contactan con el organismo, ya sea por vía respiratoria, digestiva, dérmica o mucosa. En este caso el parámetro de referencia es la Dosis Letal (DL-50), o cantidad de sustancia absorbida por kilogramo de peso.

- Corrosivos: el daño se produce por irritación o destrucción de los tejidos y materiales con los que contactan.

En cuanto a los efectos para la salud estos se caracterizan por ser de baja intensidad y a largo plazo, es decir, se absorben a bajas concentraciones durante mucho tiempo, que puede ser incluso toda la vida laboral del trabajador. Debido a esto sus efectos suelen aparecer también a largo plazo, después de muchos años de exposición. A este tipo de enfermedades se las llama crónico-degenerativas, con largos periodos de latencia y que se manifiestan en edades tardías.

Los compuestos químicos más comunes en las actividades sanitarias son:

- Agentes anestésicos inhalatorios: óxido nitroso, halotano, enflurano, etc.

- Agentes esterilizantes: óxido de etileno

- Alcoholes: metilalcohol, etilalcohol, etc.

- Aldehídos: glutaraldehido, formaldehido

- Citostáticos: metotrexato, ciclofosfamida, vimblastina, etc.

- Disruptores endocrinos: alquilfenoles, bisfenol-A, dioxinas, disolventes, etc.

- Metales: mercurio, plomo

- Residuos sanitarios

- Otros residuos: pinturas, limpiadores, desinfectantes, detergentes, biocidas, etc. 
4.2.1 Medidas preventivas generales

Las medidas de prevención hacen referencia sobre todo a (15):

- Etiquetado y fichas de seguridad: se debe exigir a los proveedores que los productos estén correctamente etiquetados y que sus fichas de seguridad estén actualizados. Además, hay que informar y formar a los trabajadores sobre estos aspectos para que sepan identificar este tipo de sustancias.

- Almacenamiento: la principal medida es que siempre se debe conservar el producto en su envase original. Además, se debe limitar el almacenamiento a la cantidad imprescindible, no se deben colocar productos incompatibles unos cerca de otros, el almacén o lugar donde se guarden debe estar suficientemente ventilado y el acceso a los productos debe estar controlado.

- Manipulación: se debe evitar el vertido libre, se deben utilizar las medidas protectoras adecuadas (guantes, gafas...) y debe haber lavaojos y duchas en los lugares de manipulación. Es decir, se deben extremar las precauciones con este tipo de productos.

\subsection{2 ¿Qué debemos saber? (a desarrollar en el plan de formación)}

- Aprender a interpretar las fichas de seguridad y conocer el diferente etiquetado de este tipo de sustancias.

- Conocer las medidas preventivas referentes a la manipulación y almacenamiento de estos productos.

\subsection{RESIDUOS SANITARIOS}

Antes de centrarnos en los riesgos de carácter físico, ergonómico y psicosocial, dedicamos un apartado a los residuos sanitarios ya que dentro de estos podemos encontrar tanto agentes biológicos como agentes químicos, ambos perjudiciales para la salud.

Cuando hablamos de residuos sanitarios hacemos referencia a todo el materia sanitario cuyo uso se da por finalizado y debe ser desechado (agujas, gasas con sangre, instrumental quirúrgico, hemoderivados, medicamentos, etc.). El correcto tratamiento de este tipo de residuos nos permitirá disminuir el riesgo que suponen para la salud y el medio ambiente. 
Los residuos generados por la actividad sanitaria se clasifican en cuatro grupos (16):

- Residuos sanitarios asimilables a residuos municipales o de tipo I: este tipo de residuos no necesitan un tratamiento especial y dentro del grupo se incluyen el papel, el cartón, material de oficina, de cafetería y residuos provenientes de pacientes no infecciosos (no incluidos en los tipos II y III).

- Residuos sanitarios no específicos o de tipo II: en este caso si se deben tomar precauciones en la manipulación, la recogida, el almacenamiento, así como en el transporte, pero solo dentro del ámbito hospitalario. Dentro de este grupo incluimos el material de curas, yesos, ropa y material de un solo uso contaminados con sangre o secreciones, etc.

- Residuos sanitarios específicos de riesgo o de tipo III: con este tipo de residuos sí se deben tomar medidas de prevención en la manipulación, la recogida, almacenamiento y transporte, tanto dentro del ámbito hospitalario como fuera del mismo, ya que se considera que pueden suponer un riesgo para la salud laboral y pública. Este grupo de residuos, a su vez, podemos clasificarlos en:

- Residuos sanitarios o infecciosos: residuos capaces de transmitir enfermedades infecciosas.

- Residuos anatómicos: restos humanos

- Sangre y hemoderivados en forma líquida: hablamos de recipientes que puedan contener sangre, hemoderivados o cualquier líquido biológico, pero siempre en forma líquida.

- Agujas y material punzante y cortante: se incluyen aquí las agujas, pipetas, hojas de bisturí, portaobjetos, cubreobjetos, capilares, material de vidrio, etc.

- Vacunas vivas y atenuadas

- Residuos tipificados en normativas singulares o de tipo IV: se trata de residuos cuya gestión está controlada de manera especial ya sea desde el punto de vista higiénico como desde el punto de vista medioambiental, tanto dentro como fuera del centro sanitario. Este tipo de residuos incluyen:

- Residuos citostáticos: restos de este tipo de medicamentos y todo el material de un solo uso que haya estado en contacto con ellos. 
- Restos de sustancias químicas: se trata de residuos contaminados con productos químicos y se incluyen aquí diversos materiales tales como pilas, termómetros, disolventes, reactivos químicos, medicamentos, etc.

- Medicamentos caducados

- Aceites minerales y sintéticos

- Residuos radioactivos: residuos contaminados con sustancias radioactivas.

- Restos anatómicos humanos con entidad: hablamos de cadáveres o restos humanos procedentes de operaciones quirúrgicas o abortos.

\subsection{1 ¿Qué debemos saber? (a desarrollar en el plan de formación) \\ - Los trabajadores deben ser capaces de identificar los diferentes tipos de residuos sanitarios que se encuentran durante su actividad laboral y conocer la gestión que se debe hacer con cada tipo de residuos para poder ponerla en práctica. \\ - Una vez clasificados los diferentes tipos de residuos sanitarios, se deben conocer las medidas que se adoptan para su recogida, transporte intracentro, almacenamiento, tratamiento y eliminación.}

\subsection{RIESGOS FÍSICOS}

Entre los riesgos físicos, el más destacable de todos ellos es la exposición a energía electromagnética o radiaciones, que dependiendo del servicio clínico en el que el trabajador desarrolle su tarea, estará más o menos expuesto a ellas.

Las radiaciones podemos dividirlas en radiaciones ionizantes (rayos $\mathrm{X}$, rayos gamma, partículas alfa, etc.) y las radiaciones no ionizantes (la luz ultravioleta, la luz infrarroja, líneas de alta tensión, telefonía móvil, etc.).

En los centros sanitarios existe exposición a radiaciones debido a los servicios de radiodiagnóstico, de radiología, radioterapia, rehabilitación, los láseres utilizados en cirugía, dermatología, oftalmología, la luz ultravioleta utilizada en esterilización, la proliferación de teléfonos móviles y redes wi-fi, etc.

En cuanto a los efectos para la salud, los riesgos laborales suelen estar relacionados con la intensidad y frecuencia de las radiaciones, así como con las características específicas del 
trabajador (embarazos, portadores de marcapasos). En principio, dentro de los niveles de radiación recomendado no existen efectos perjudiciales para la salud, pero sí se recomienda fomentar el control sanitario y la vigilancia epidemiológica a la exposición con el fin de evaluar los posibles efectos a medio y largo plazo (17).

Dependiendo del tipo de radiación no ionizante, los efectos a la salud serán diferentes pero podemos agruparlos en:

- Piel: pigmentación de la piel, eritemas, quemaduras

- Daños oculares: fotoqueratitis, cataratas, daños en la retina, lesiones en la córnea

- Inhalación de productos tóxicos generados por la radiación láser

Los efectos para la salud de las radiaciones ionizantes son muy peligrosos y además, el organismo humano no es capaz de detectarlos por lo que una exposición puede pasar desapercibida hasta que no aparecen los efectos. Este tipo de radiaciones tienen un elevado poder de penetración, por lo que pueden atravesar la materia y producir rotura de átomos y moléculas. A nivel de nuestro organismo esto se traduce en interferencia con los procesos de división celular y generación de mutaciones, por lo que los posibles efectos pueden ser diferentes, en función de la dosis absorbida:

- Malformaciones fetales, nauseas, fatiga, vómitos

- Esterilidad

- Problemas en la piel, caída de cabello

- Hemorragias, hipertiroidismo

- Y a largo plazo, cataratas, cáncer, leucemia, daño genético, etc.

\subsubsection{Medidas preventivas generales}

Las principales medidas de protección contra las radiaciones no ionizantes son:

- Utilización de los equipos únicamente durante el tratamiento del paciente.

- Extremar las medidas de precaución en cuanto a la distancia de seguridad, tiempo de exposición, reducción de la potencia de radiación. También tener en cuenta que la separación de los distintos equipos entre si es necesaria. 
- Realización de los controles de calidad de los equipos, de los mantenimientos periódicos y reparaciones necesarias.

- Control sanitario y epidemiológico de la exposición.

- Uso de equipos de protección adecuados.

- Colocación de pantallas metálicas conectadas a tierra, de manera que la energía que transportan pueda ser absorbida por ésta.

En cuanto a las radiaciones ionizantes, la principal medida es que su utilización debe estar plenamente justificada en función de los beneficios que aporta, y además su uso se debe efectuar de manera que la exposición afecte al mínimo número de personas (trabajadores, pacientes, estudiantes).

Además:

- Se debe realizar una evaluación de las condiciones laborales y de la magnitud del riesgo radiológico, asegurando siempre el principio de optimización.

- Se deben clasificar tanto los lugares de trabajo (en diferentes zonas en función de las dosis anuales previstas, el riesgo de dispersión, la contaminación, etc.), como el personal expuesto (diferentes categorías en función de las condiciones en las que trabajan).

- Vigilancia sanitaria y aplicación de la normativa vigente y medidas de control.

\subsection{2 ¿Qué debemos saber?}

- Los profesionales deben conocer los diferentes tipos de radiaciones existentes y sus efectos para la salud.

- Se les debe enseñar a discriminar entre las diferentes radiaciones a las que se exponen en función del tipo de trabajo que realizan.

- Deben conocer las medidas de prevención necesarias para evitar posibles daños a su salud y notificar aquellas medidas que crean que no se cumplen. 


\subsection{RIESGOS ERGONÓMICOS}

La ergonomía, principalmente se centra en el diseño de los puestos de trabajo de forma que estos se adapten a las capacidades y limitaciones de las personas que los ocupan, y de esta forma poder prevenir los daños a la salud, sobre todo, los trastornos musculoesqueléticos. En la guía de "Prevención de trastornos musculoesqueléticos en el sector sanitario" podemos ver que el año 2011, un 38.5\% de los accidentes laborales que se notificaron fueron debidos a sobreesfuerzos. Además, en la VII Encuesta Nacional de Condiciones de Trabajo vemos que un $84 \%$ de los trabajadores afirma tener molestias que se deben a posturas o condiciones físicas de su trabajo. Existe una elevada incidencia de este tipo de trastornos en aquellos trabajadores que se dedican al cuidado de pacientes o que desarrollan su actividad laboral en centros sanitarios.

En un estudio realizado en una red de hospitales asociados a la Mancomunitat Sanitària de Prevenció (aMSP), durante los años 2005-2010, vemos que la segunda causa de siniestralidad en el ámbito sanitario son los accidentes por sobreesfuerzo, siendo la primera de ellas los accidentes biológicos (18).

Si analizamos los diferentes tipos de sobresfuerzos (manipulación manual de cargas, movilización de enfermos, malos gestos o posturas y movimientos repetitivos) observamos que, un $60 \%$ del total de accidentes ocasionados por sobresfuerzos se deben a la movilización de enfermos. En cuanto al servicio donde son más frecuentes este tipo de accidentes (hospitalización, urgencias, quirófanos, radiología, $\mathrm{UCl}$, centro de día, consultas, etc.), el $72.54 \%$ de accidentes tienen lugar en el servicio de Hospitalización. Este tipo de accidentes afectan más a los auxiliares de clínica (52.89\%), pero los datos referentes a enfermería también son interesantes porque nos indican que un $17,65 \%$ de estos profesionales sufre este tipo de accidentes, y la principal causa sigue siendo la movilización de enfermos.

Por esta razón es necesario formar a este colectivo sobre las medidas preventivas que deben adoptar en estos casos para prevenir los trastornos musculoesqueléticos asociados a este tipo de accidentes. 
En el sector sanitario se consideran riesgos ergonómicos:

- La manipulación de cargas: destaca en este grupo la movilización de enfermos, muy frecuente en el personal sanitario.

- La higiene postural: importante en el desarrollo de cualquier actividad y sobre todo en la manipulación de cargas.

- Los movimientos forzados: pueden provocar contracturas y lesiones musculares, ya sean realizados con o sin carga.

- El sedentarismo: la falta de actividad hace que la musculatura esté débil, siendo más susceptible de sufrir lesiones.

- Los movimientos imprevistos: suele ocurrir cuando el paciente realiza un movimiento inesperado. En este caso el profesional sanitario suele reaccionar de manera imprevista y puede realizar movimientos bruscos que le pueden ocasionar lesiones.

- La visualización de pantallas de datos (VPD): el uso de los ordenadores es cada vez más frecuente y las malas posturas adoptadas por los usuarios, así como la incorrecta colocación de los equipos, pueden ser causa de lesiones musculares.

\subsubsection{Medidas preventivas generales}

La principal medida de prevención en la manipulación de cargas sería eliminar el riesgo, es decir, no manipular cargas de manera manual y utilizar equipos mecánicos para esta tarea. Si esto no es posible, se debe modificar la tarea manipulando cargas de menor peso o disminuyendo la frecuencia del trabajo. También se debe tener en cuenta la posibilidad de mover la carga en equipo o adaptar el peso de esta a las características de la persona que la tiene que manipular. Es importante resaltar que siempre es mejor empujar de la carga que tirar de ella, y en caso de que tengamos que llevarla en peso, recordar que el transporte debe ser con la carga pegada al cuerpo y la espalda recta.

Con la movilización de enfermos nos encontramos que la carga tiene unas características específicas como son el elevado volumen y peso de la misma, la dificultad que puede suponer sujetar al enfermos sobre todo si este pone resistencia, y los movimientos que realiza el personal sanitario durante esta tarea, en los que suele realizar giros a la misma vez que eleva o desplaza al paciente. Una de las medidas preventivas es planificar y organizar cómo se va a realizar el movimiento del paciente. Cuando vamos a realizar este tipo de tareas lo principal es hacerlo 
entre varios trabajadores, planificando cómo se van a realizar los movimientos y conociendo cada uno de ellos su función. También se deben conocer los principios básicos de la higiene postural para que los adoptemos en este tipo de situaciones. Lo ideal sería formar a los trabajadores en técnicas de movilización de pacientes para que conozcan las diferentes posibilidades de movilización que hay y aprendan a realizarlas correctamente. Por último, si el paciente es muy pesado, se debe recurrir a equipos mecanizados para realizar la movilización.

En cuanto a la visualización de pantallas de datos los daños a la salud que se pueden ocasionar no solo están relacionados con las lesiones musculoesqueléticas, sino también con daños a la vista o incluso la generación de estrés. Según el RD 488/19975, consideraremos que existe riesgo en aquellos trabajadores que utilicen equipos de PVD durante más de cuatro horas diarias o que en transcurso de una semana de trabajo superen las 20 horas de trabajo con los mismos. Las principales medidas preventivas que debemos tener en cuenta hacen referencia al diseño del puesto de trabajo. El diseño del puesto de trabajo debe ser el indicado para mantener las condiciones ergonómicas correctas (uso de sillas apropiadas, de atriles, de reposapiés regulables, ajustar el mobiliario al trabajador, etc.), y además, se debe formar al trabajador para que adopte posturas de trabajo correctas, informarle de la necesidad de realizar pausas y de realizar movimientos de relajación y estiramientos (19).

\subsection{2 ¿Qué debemos saber?}

- En el caso de la manipulación de cargas, debemos conocer los factores de riesgo asociados a la manipulación de cargas.

- Para la movilización de enfermos se deben conocer las diferentes técnicas de movilización existentes:

- Paciente dependiente:

- Incorporación en la silla

- Incorporación en la cama

- Movimiento de la cama a la silla

- Posición decúbito lateral

- Desplazamiento longitudinal

\footnotetext{
${ }^{5}$ Real Decreto 488/1997, de 14 de abril, sobre disposiciones mínimas de seguridad y salud relativas al trabajo con equipos que incluyen pantallas de visualización. BOE no 97 23/04/1997.
} 
- Levantamiento desde el suelo

- Paciente semidependiente:

- Sentar al paciente en el borde de la cama

- Movilización de la cama a la camilla

- Movilización de la cama a la silla

- En el caso de las PVD se debe enseñar a los trabajadores las posturas de trabajo que deben adoptar para evitar la aparición de lesiones. Deben conocer la necesidad de utilizar atriles y reposapiés, y saber la importancia que tiene el diseño del puesto de trabajo para que sean capaces de observar las incorrecciones y notificarlas, con el fin de subsanarlas.

\subsection{RIESGOS PSICOSOCIALES}

Los factores psicosociales son condiciones organizacionales generales que se encuentran en cualquier tipo de organización y que hacen referencia a la gestión y organización de la misma, así como al liderazgo, al clima laboral y al desarrollo personal y profesional de los trabajadores (20).

Cuando estas condiciones de trabajo pueden afectar a la salud (física o psicológica) y al bienestar de los trabajadores, actuando como factores desencadenantes de tensión y estrés laboral, hablamos de factores de riesgo psicosocial. Los principales efectos sobre la salud de los trabajadores suelen ser la generación de estrés laboral, el Síndrome de estar Quemado con el Trabajo o Burnout y la violencia. Estos factores suelen estar relacionados con las características del trabajo, su organización, el contenido del puesto de trabajo, la realización de una tarea, con el entorno laboral, la carga física o mental del trabajo, la ambigüedad de rol, etc. La exposición a estos factores puede afectar a la salud del trabajador, pero esto dependerá de las estrategias que adopte el trabajador para manejar estas situaciones, ya sea bien adaptándose a la situación o modificando su comportamiento, sus conocimientos o sus emociones (21).

Además de los riesgos psicosociales tradicionales, actualmente se habla de los riesgos psicosociales emergentes, que según la Agencia Europea para la Seguridad y Salud en el Trabajo, se definen como aquellos riesgos nuevos que van en aumento, y que se agrupan en: 
- Nuevas formas de contratación e inseguridad laboral

- Envejecimiento de la población activa

- Intensificación del trabajo

- Fuertes exigencias emocionales en el trabajo

- Desequilibrio entre la vida laboral y personal

\subsubsection{Medidas preventivas generales}

La prevención de los riesgos psicosociales, así como las estrategias de intervención, se pueden plantear desde un punto de vista organizacional o individual a nivel del trabajador (o una combinación de ambas) (22).

A nivel organizacional:

- Intentar adecuar el puesto de trabajo a la persona que lo realiza.

- Intentar que el ritmo de trabajo, su contenido y la responsabilidad asociada al trabajo realizado estén acordes, para que no sea ni excesivo ni escaso en función de las capacidades del trabajador.

- Especificar un sistema de promoción y desarrollo adecuados a los trabajadores. La formación de los trabajadores debe estar planificada y programada en función de las expectativas de los trabajadores.

- Favorecer la comunicación entre todos los integrantes de la empresa así como sistemas de información para que todos los empleados se impliquen en la organización.

- Establecer sistemas de resolución de conflictos.

A nivel individual:

Las estrategias individuales que se están llevando a cabo actualmente para prevenir este tipo de riesgos se basan en la Psicología Positiva, que es un enfoque de la psicología que se centra en la experiencia óptima y en el análisis de aquello que hace que la vida merezca la pena ser vivida (23).

Las prácticas organizacionales que se ha visto que tienen mayor impacto positivo en la salud de los trabajadores son las que se refieren a la conciliación trabajo-familia, a la prevención del 
mobbing, al desarrollo de habilidades psicosociales y de comunicación, al desarrollo de la carrera profesional y de la responsabilidad, a la equidad, etc. (24).

\subsection{2 ¿Qué debemos saber?}

- Conocer los factores de riesgo asociados a la aparición de estrés laboral, así como los principales síntomas del estrés. De esta forma, por un lado el trabajador podrá tomar las medidas oportunas para prevenir el estrés laboral, y por otro, será capaz de reconocer si se encuentra en una situación de estrés y podrá solicitar la ayuda necesaria.

- Entrenar a los trabajadores en las diferentes técnicas que permiten crear trabajadores "positivos", de manera que podamos mejorar algunas características individuales de los trabajadores, como son las habilidades profesionales y sociales o emocionales, la autoeficacia, las habilidades de comunicación, el liderazgo, etc.

- Enseñar a los trabajadores las estrategias de afrontamiento para este tipo de riesgos. 


\section{COMUNICACIÓN Y FORMACIÓN EN PREVENCIÓN DE RIESGOS LABORALES}

\subsection{EL PROCESO DE COMUNICACIÓN}

La comunicación en prevención de riesgos laborales se debe entender como una vía de doble sentido, es decir, tan importante es la comunicación por parte de la empresa hacia los trabajadores sobre la existencia de riesgos y las medidas de prevención que se deben adoptar, como la comunicación por parte de los trabajadores hacia la empresa notificando los posibles riesgos encontrados durante el desempeño de su trabajo. Por lo tanto es importante facilitar o crear vías de comunicación que nos ayuden a cumplir ambos objetivos, ya que con ambos podemos conseguir el perfeccionamiento de la actividad preventiva en la empresa.

Centrándonos en la definición de comunicación, podríamos definirla como un proceso mediante el cual dos individuos interaccionan entre sí. Pero actualmente, a nivel de empresa u organizaciones, la comunicación es algo mucho más importante, es decir, es tanto el soporte que ayuda a las organizaciones a estar unidas y trabajar conjuntamente y en armonía, así como un recurso que nos permite implantar actividades de mejora continuada (25).

\subsubsection{Comunicación por parte de la empresa hacia el trabajador}

La empresa tiene la obligación de informar a los trabajadores en cuanto a la existencia de los riesgos laborales, las medidas preventivas para evitarlos y las acciones que se deben desarrollar si se produce algún accidente.

Todos los profesionales sanitarios están sometidos a una serie de riesgos laborales generales que son más o menos comunes a todos, pero si nos centramos en el colectivo de enfermería, este desarrolla un trabajo específico sujeto a una serie de riesgos que deben conocer y saber evitar. Por esta razón es muy importante que cuando se comunica a estos profesionales los riesgos laborales, se haga relacionándolos con el trabajo que realizan. Es decir, intentar especificar lo máximo posible la información que aportamos porque de esta manera implicamos más a los profesionales y conseguimos que se sientan como parte de la empresa.

La empresa o el servicio de prevención de la misma son los responsables de organizar los cursos de formación en prevención de riesgos laborales y lo ideal sería, que aunque impartan cursos generales para todos los profesionales del centro sanitario, también se impartan cursos 
específicos para cada perfil profesional (médicos, enfermería, auxiliares, etc.). Lo mismo ocurre con la comunicación de riesgos, se deben hacer campañas generales y campañas más definidas en función de los riesgos de cada colectivo.

Existen una serie de requisitos necesarios para conseguir una comunicación efectiva:

- Claridad: se debe ser muy claro con aquello que queremos transmitir para que todo el mundo pueda captarlo.

- Integridad: la comunicación debe perseguir la cooperación de todos los integrantes de la empresa, con el fin de facilitar la mejora de objetivos.

- Intentar aprovechar la comunicación informal: los canales de comunicación formales (correos, circulares, etc.) suelen ser más aburridos para los trabajadores. Se debe innovar el proceso de comunicación con acciones más visuales y generales, más que aquellas que van dirigidas a cada trabajador de manera individual.

- Moderación y equilibrio: no se debe abusar del proceso de comunicación, sino que se debe tener un plan de acción administrativo y comunicar lo estrictamente necesario y de la forma más concisa posible.

- Difusión: se debe intentar que la difusión del mensaje que se quiere transmitir sea lo más amplia posible, así como intentar que sea siempre por escrito.

- Evaluación: los sistemas y canales de comunicación deben revisarse y perfeccionarse en caso necesario, de manera periódica.

Cuando iniciamos el proceso de comunicación también debemos tener en cuenta una serie de barreras que pueden dificultar la transmisión del mensaje. Se trata de barreras físicas, semánticas y psicológicas. Estas últimas son las más complicadas de resolver ya que están relacionadas con las emociones, los valores, las percepciones y los hábitos de conducta, por lo que se deberán tener en cuenta a la hora de establecer las vías de comunicación y la formación necesaria en riesgos laborales $(26,27)$.

En la página del Instituto Nacional de Seguridad e Higiene en el Trabajo, en el Portal de Promoción de la Salud en el Trabajo, encontramos la campaña "Gana en Salud: 12 temas, 12 meses". La estrategia que se sigue en esta campaña nos puede ayudar a establecer una vía de comunicación con los trabajadores, más visual y efectiva. Con esta campaña se trata de llegar de 
manera individual a cada uno de los trabajadores para establecer una cultura de prevención y salud en la empresa. Adaptando esta estrategia a los fines que nosotros queremos conseguir, también podemos concienciar a los profesionales sanitarios de los diferentes riesgos laborales que afrontan en su trabajo diario.

En nuestro caso elegiríamos aquellos temas relacionados con los riesgos laborales en enfermería que creamos más convenientes, para abordarlos de manera mensual durante todo el año. El primer paso, semana 1, sería realizar carteles con dibujos relacionados con el tema elegido. Al tratarse únicamente de dibujos llamaríamos la atención de los profesionales, a los cuales les surgirían dudas y preguntas. La segunda semana se repetiría el proceso pero a los carteles se les añadiría texto, de esta forma se resolverían las dudas iniciales en los profesionales. La tercera semana se realizaría una reunión para que los participantes puedan participar en la exposición de ideas sobre el tema y debatir sobre ello. En este punto sería importante la implicación de los mandos intermedios. Por último, la cuarta semana, se entregaría de manera individual un folleto sobre el tema tratado con el fin de transmitir consejos que se puedan poner en práctica fácilmente y conseguir una reflexión sobre el tema que tratamos por parte de estos profesionales (28).

Esta iniciativa tiene sus ventajas e inconvenientes. Entre las primeras podemos mencionar que se trata de una forma innovadora de tratar la prevención de riesgos laborales y de hacerlo de forma continuada durante todo el año, de forma que conseguiríamos una mayor implicación por parte de los trabajadores. También es una forma divertida de ver la prevención y de introducirla en los temas de conversación diarios de los trabajadores.

Entre los inconvenientes, uno de los más importantes sería el tema económico, seguido del de recursos humanos. Para llevar a cabo esta campaña cada mes se necesita realizar un trabajo para el que a veces no hay suficiente personal contratado en los servicios de prevención. Si además añadimos que la idea sería realizarlo para los diferentes colectivos profesionales que encontramos en los centros sanitarios, dificultamos la tarea.

A la hora de establecer vías de comunicación con los trabajadores también debemos utilizar las nuevas tecnologías, incluidas ya casi de manera definitiva en el ambiente laboral. Podemos utilizar tanto la intranet del centro sanitario, como el correo electrónico, para enviar 
determinados mensajes, aunque el impacto de estas vías de comunicación suele ser menor ya que requiere un acostumbramiento por parte del trabajador a realizar visitas a la intranet o a revisar su correo electrónico diariamente (29).

Dentro de la comunicación por parte de la empresa hacia a los trabajadores incluiríamos la formación como proceso de aprendizaje teórico y práctico de los principales riesgos laborales asociados a la profesión de enfermería y las principales medidas preventivas asociadas a estos.

Como ya se ha mencionado, existen una serie de barreras que pueden afectar al proceso de comunicación y formación y entre las cuales destacamos como más importantes las barreras psicológicas, relacionadas, sobre todo, con las percepciones y los hábitos de conducta. Es importante tener este punto en cuenta a la hora de diseñar un programa de formación porque eliminar malos hábitos de conducta es un proceso complejo, y la percepción del riesgo también es una cuestión difícil de resolver. Normalmente estos dos comportamientos están relacionados, ya que cuando un profesional no percibe el riesgo que puede llevar una determinada acción, normalmente no la ejecuta bien (en relación a la prevención de riesgos), por lo tanto hay que incidir en la necesidad de que perciba esa acción como un riesgo para que así podamos ayudarle a modificar su conducta respecto a ella.

\subsubsection{Comunicación por parte del trabajador hacia la empresa}

La identificación de riesgos es una de las cosas más importantes en la prevención de accidentes y enfermedades profesionales, ya que no se puede actuar contra aquello que no se conoce.

La detección de riesgos se suele realizar mediante el proceso de evaluación y la investigación de accidentes, pero la comunicación de riesgos por parte del trabajador es un mecanismo muy valioso ya que permite a los trabajadores dar a conocer situaciones laborales que ellos perciben como peligrosas a las personas que pueden corregirlas, los mandos intermedios o superiores.

En la Ley de Prevención de Riesgos Laborales, en su artículo 29, queda plasmada la obligación por parte de los trabajadores de "informar de inmediato a su superior jerárquico directo, y a los trabajadores designados para realizar actividades de protección y de prevención o, en su caso, al servicio de prevención, acerca de cualquier situación que, a su juicio, entrañe, por motivos razonables, un riesgo para la seguridad y la salud de los trabajadores". 
En este proceso de comunicación de riesgos por parte del trabajador hacia la empresa es muy importante la formación que hayan recibido los trabajadores en materia de prevención de riesgos, ya que sin los suficientes conocimientos sobre este tema, difícilmente serán capaces de reconocer situaciones de riesgo.

Además de los profesionales de enfermería, debemos tener presente que los alumnos de prácticas de enfermería también son una fuente importante de información en este sentido. Normalmente, el número de alumnos que pasan por los centros sanitarios es elevado ${ }^{6}$ y se trata de futuros profesionales que han adquirido los conocimientos teóricos en prevención de riesgos laborales durante su formación universitaria, pero que no los han puesto en práctica todavía. Es decir, aún no han adquirido malos hábitos de conducta y si perciben los riesgos como tal, porque no tienen la suficiente confianza en su trabajo diario como para no percibir los riesgos. Por lo tanto, queríamos destacar que sería favorable utilizarlos como fuentes de información en cuanto a la detección de riesgos laborales.

Sin embargo, si observamos la Guía Docente del Grado de Enfermería (2016-2017) de la Universidad de Murcia (30), podemos observar que no hay ninguna asignatura que sea específica de Prevención de Riesgos Laborales en ninguno de los cuatro cursos universitarios. El primer año si hay asignaturas que hacen referencia a la seguridad del paciente, pero no a la seguridad del profesional. En el segundo año tenemos la asignatura "Bases de la Enfermería Comunitaria y Educación para la Salud), que va enfocada a la Promoción de la Salud más que a la prevención de riesgos laborales. Y en el tercer año tampoco vemos ninguna asignatura destinada a formar a los alumnos en prevención de riesgos.

En cuanto a la formación práctica de esta carrera universitaria, el Grado de Enfermería tiene una duración de cuatro años y las prácticas en centros sanitarios se inician el segundo año, durante el cual, los alumnos realizan dos meses de prácticas, normalmente en hospitalización. El tercer año vuelven a realizar prácticas, combinando hospitalización y quirófanos, y por último, el cuarto año lo dedican prácticamente en su totalidad a realizar prácticas, ya sea en Centros de Atención Primaria, en Urgencias y SUAP o en Especialidades (cárceles, psiquiatría, neonatos, hemodonación o diálisis).

\footnotetext{
${ }^{6}$ Normalmente, el número de alumnos de Enfermería suele oscilar entre los 150-200 alumnos por año académico.
} 
Consultados algunos alumnos de prácticas, comentan que antes de iniciar las prácticas el segundo año de estudios reciben unos seminarios teórico-prácticos sobre prevención de riesgos, pero según ellos, insuficientes para enfrentarse por primera vez a un entorno profesional en un centro sanitario.

Por lo tanto, podemos intuir que la formación teórica que reciben los alumnos de prácticas de enfermería antes de iniciar dichas prácticas no es suficiente para detectar los posibles riesgos laborales a los que se exponen y las medidas preventivas para evitarlos, así que lo ideal sería que al iniciar las prácticas, la formación necesaria en prevención de riesgos laborales quedase a cargo del centro sanitario en el cual las realicen. De esta forma los alumnos estarán preparados para detectar las posibles deficiencias en materia de riesgos laborales y la información que proporcionen será útil para mejorar la calidad de la prevención de riesgos.

Basándonos en la NTP 561 del INSHT (31), a continuación proponemos unas recomendaciones que se podrían establecer para conseguir una vía de comunicación de riesgos efectiva y mayor participación, tanto por parte de los profesionales de enfermería como por parte de los alumnos de prácticas:

- La principal recomendación sería una formación adecuada en materia de prevención de riesgos laborales de todos los trabajadores de la empresa, así como de los alumnos de prácticas en el momento en el que estas comiencen. Sin una formación adecuada, difícilmente serán capaces de detectar los riesgos laborales susceptibles de ser mejorados.

- Se debe informar a los trabajadores y a los alumnos de prácticas de la existencia de esta vía de comunicación de riesgos y del funcionamiento de la misma, para concienciarlos de la importancia y la repercusión que tendrá el utilizarla.

- Para que la implantación de esta vía de comunicación sea efectiva, es necesario un compromiso por parte de la dirección y los mandos superiores que además deben transmitir a los mandos intermedios y a todos los trabajadores.

- Se debe contribuir a mejorar el diálogo, el aporte de ideas y de soluciones, y así conseguir que todos los trabajadores se sientan implicados en la mejora de las condiciones de trabajo y por tanto, en el desarrollo de su trabajo. 
- Es importante comunicar las soluciones adoptadas respecto a las ideas comunicadas por parte de los trabajadores, para que estos vean que sus sugerencias son estudiadas y analizadas por las personas responsables de la prevención de riesgos. Sería conveniente que el Servicio de Prevención estimulase a los trabajadores en este sentido, con charlas o reuniones a lo largo del año en las que se haga un resumen de los riesgos detectados y las medidas adoptadas para corregirlos.

- Una comunicación de riesgos errónea también nos permitirá detectar deficiencias en la formación de los trabajadores, por lo que nos ayudaría a mejorar el proceso de formación.

- Se debe elaborar un documento de comunicación de riesgos, tipo formulario y fácil de rellenar, para que al trabajador no le resulte un inconveniente hacerlo. Además, sería necesario resaltar la importancia de que la comunicación de riesgos se realice de forma escrita y no verbal. De esta manera aseguramos que se adopten las medidas oportunas y el seguimiento de las soluciones adoptadas.

- No se recomienda incentivar económicamente la comunicación de riesgos, pero si alguna de las soluciones aportadas por un trabajador es llevada a cabo con éxito y la correspondiente mejora, si se aconseja establecer un mecanismo de compensación transparente. Es decir, un reconocimiento individual o colectivo a este trabajador, es un buen estímulo para conseguir la cooperación de todos ellos.

En el Anexo I proponemos un ejemplo de lo que podría ser un Documento de Comunicación de Riesgos. En este documento debería constar la identificación del trabajador que lo rellena (nombre, puesto de trabajo y servicio clínico), si lo que propone es un riesgo detectado o es una propuesta de mejora, la descripción de su propuesta, y si se trata de un riesgo detectado, y el trabajador tiene una posible solución, darle la opción de expresarla.

\subsection{EL PROCESO DE FORMACIÓN}

En el ámbito de la salud, la evolución del proceso de formación no ha seguido el mismo ritmo que la evolución de las nuevas tecnologías, más concretamente de las Tecnologías de la Información y de la Comunicación (TIC). La necesidad de una formación continuada de los sanitarios a lo largo de toda su carrera profesional es algo en lo que la mayoría de los profesionales están de acuerdo, debido al hecho de que es conveniente estar actualizado para 
poder cubrir correctamente las necesidades asistenciales. La introducción de las TIC en el proceso de enseñanza de este colectivo nos permite facilitar la formación continuada, pero no siempre son bien acogidas por parte de los participantes.

La enseñanza virtual, online o e-learning, queda definida por la Fundación para el Desarrollo de la Función Social de las Comunicaciones (FUNDESCO) como "un sistema de impartición de formación a distancia, apoyado por las TIC que combina distintos elementos pedagógicos: introducción clásica (presencial o autoestudio), las prácticas, los contactos en tiempo real (presenciales, videoconferencias o chats) y los contactos diferidos (tutores, foros de debate, correo electrónico) (32).

La opinión generalizada suele ser que este tipo de formación es una formación impersonal, superficial, que no siempre está bien enfocada a las necesidades de los alumnos y que en definitiva, aunque permite una mayor flexibilidad horaria, no siempre es lo eficiente que debería ser.

Un estudio realizado en España sobre las necesidades formativas de las organizaciones (33) resalta que el $95 \%$ de las empresas cree que la formación online no es una moda pasajera. Además, se obtienen elevados porcentajes en las cuestiones que hacen referencia a que la formación online recoge temas interesantes, ofrece formación de acuerdo a las necesidades de los alumnos y existe una buena relación calidad-precio. No obstante, respecto si este tipo de formación es bien recibida por los empleados, sólo un 58\% de las empresas participantes en el estudio opina que si es bien recibida, y una $44 \%$ afirma que la calidad de la formación online es igual o superior a la de la formación presencial.

Otro estudio realizado sobre las percepciones de los profesionales sanitarios en Alemania, España y Estados Unidos sobre la formación online ofrece resultados interesantes, como por ejemplo, que el uso de las TIC como herramienta formativa disminuye conforme aumenta la edad de los profesionales. Otro dato interesante es que de los tres países analizados, el que peor accesibilidad presenta a la formación online es España (34). La mayoría de los profesionales consultados en Alemania y Estados Unidos considera que la educación presencial y la educación online se adapta a sus necesidades, siendo España el único país en el que un $15 \%$ de los profesionales consultados cree que sus necesidades formativas no están cubiertas, coincidiendo 
este porcentaje con el del número de personas que nunca habían recibido formación online. Por lo tanto, deberíamos plantearnos la necesidad de adaptar las estrategias de formación para los profesionales sanitarios españoles, de manera que les podamos ayudar a conseguir una mayor accesibilidad a la formación continuada.

Un estudio realizado con estudiantes universitarios nos revela también las debilidades y fortalezas que estos perciben en la formación online (35).

Según este estudio, la principal ventaja que perciben los universitarios, respecto al uso de las TIC en la formación, es la posibilidad que ofrece a los estudiantes que trabajan de poder compatibilizar sus estudios, así como la posibilidad de autorregular su propio aprendizaje. Este punto es importante para nosotros ya que lo que pretendemos es que los trabajadores sanitarios también puedan compatibilizar su labor con la formación continuada, y adaptar la formación a sus horarios y necesidades. Entre las principales debilidades de la formación online que señala este estudio destacamos la ausencia de interacción cara a cara, tanto entre los alumnos como entre estos y los profesores. Sin embargo esta debilidad se puede subsanar con la incorporación de foros, debates y una plataforma que incorpore un perfil de usuario que permita introducir una foto, tanto del alumno como del profesor.

A pesar de todo, no debemos olvidar que, actualmente, el uso de las TICs en el proceso de enseñanza-aprendizaje de las universidades europeas juega un papel decisivo a la hora de alcanzar los retos educativos de los diferentes sistemas educativos. Otro estudio realizado por la Universidad de Vigo sobre las ventajas del uso de las TICs, pero en este caso desde el punto de vista de los docentes, nos ofrece resultados similares al anterior (36). Los docentes señalan como ventaja la ruptura de las barreras espacio-temporales, la creación de procesos formativos abiertos y flexibles, mejora en la comunicación entre los alumnos y profesores, enseñanza más personalizada, acceso más rápido a la formación y mayor posibilidad de interactuar con esta información, aumento del interés y motivación de los estudiantes, mejora en la eficacia educativa, etc. Entre las principales desventajas que señalan los docentes es que el uso de las TICs les resta tiempo para dedicarlo a otras tareas y la importancia de seleccionar información fiable, ya que el aumento o disponibilidad de información en la red es considerable, y no toda ella está lo suficientemente contrastada. 
Por lo tanto, aunque la formación online se perfila como una solución a los problemas que la enseñanza tradicional no puede dar respuesta, por sí sola no garantiza una educación de mayor calidad ni un mayor rendimiento en el aprendizaje, ya que depende tanto de los contenidos ofrecidos por el profesor, de la metodología utilizada por éste y del correcto seguimiento del proceso formativo, como del interés y motivación por parte del alumno de utilizar los recursos disponibles para aprender $(37,38,39)$.

Y, ¿cuáles son las características distintivas de la formación online?

Las principales características de este tipo de formación, que la diferencia de la formación tradicional son (40):

- Favorece que los alumnos vayan a su propio ritmo de aprendizaje /parte de una base de conocimientos y son los alumnos los que deben ajustarse a ella.

- Se trata de una formación basada en el concepto de formación en el momento en el que se necesita (just-in-time trainning)/ Los profesores son los que determinan cuándo y cómo los alumnos recibirán los materiales formativos.

- Se combinan diferentes materiales (auditivos, visuales, audiovisuales)/ se suele apoyar en materiales impresos y en el profesor como fuente de información

- Suele ser una formación individual / Es una formación preferentemente grupal

- Suele ser interactiva, tanto entre el profesor y el alumno, como entre todos los alumnos / la comunicación suele ser básicamente entre profesor y alumno

- Puede realizarse en función del tiempo libre del alumno / se suele realizar en un tiempo y lugar concreto

- Es flexible / suele ser más estricta en cuanto a temporalización

- La experiencia que tenemos respecto a su uso todavía no es mucha / tenemos mucha experiencia en su uso

- No siempre se dispone de los recursos necesarios, tanto estructurales como organizativos, para su puesta en marcha / si se suele disponer de este tipo de recursos ya que su uso está mucho más generalizado 
Tanto la formación online como la formación presencial presentan sus ventajas e inconvenientes, y debido a esto, se ha empezado a utilizar un concepto que no es más que la combinación de ambas, y se trata del Blended Learning.

El término blended learnin (41) ha surgido durante los últimos años debido a las deficiencias que la formación online ha mostrado en el proceso formativo. Estas deficiencias principalmente hacen referencia a los diferentes estilos de aprendizaje de los alumnos, a las habilidades en cuanto a lectura y comprensión que estos presentan, su capacidad para organizarse el trabajo, la autodisciplina, la periodicidad necesaria para la continuidad formativa y sobre todo a la calidad de los contenidos de esta formación. El blended learning se puede definir como la combinación de la enseñanza presencial con la enseñanza no presencial, y no es realmente un concepto nuevo, ya que siempre se han combinado las clases magistrales con la realización de prácticas, pero sí es un concepto que resurge con la idea de mejorar el proceso de formación online tan de moda en estos tiempos. No existen muchos estudios que nos puedan asegurar que este tipo de formación sea mejor o peor que la formación online o la formación presencial a nivel individual, pero sería lógico pensar que una combinación de ambas nos permitirá mejorar el proceso de enseñanza ya que nos permitirá resaltar las ventajas que ambos tipos de formación poseen. Por esta razón, en el plan de formación que proponemos en este trabajo pretendemos combinar la formación presencial con la formación online. De manera tradicional, la formación presencial es la que se ha ido utilizando en los cursos de prevención de riesgos laborales dirigidos a los profesionales sanitarios. Sin embargo, si combinamos ambos tipos de formación, por un lado, con la formación presencial nos acercaremos más al alumnado para hacerles comprender la importancia de la prevención de riesgos laborales, realizar prácticas respecto a temas concretos, compartir opiniones, generar debates etc., y por otro, con la formación online conseguiremos una formación más continuada del alumnado, que por otra parte, como ya tendrá los conocimientos base a partir de la formación presencial, se verá más implicado para la realización de la formación online.

Antes de presentar el plan de formación, se resaltarán una serie de recomendaciones que debemos tener en cuenta a la hora de elaborar los contenidos para una correcta formación online (42) y a las cuales intentaremos dar respuesta con la presentación de nuestro plan de formación dirigido a los profesionales de enfermería: 
- ¿Quiénes son los estudiantes a los que va dirigida la formación?

- ¿Qué objetivos tengo con la realización de este curso? ¿Qué quiero que mis alumnos sepan o sientan durante este curso?

- ¿Qué guía o normas necesito para la realización de este curso?

- ¿Cómo planifico el curso? ¿Qué puede ofrecer a los alumnos la combinación de una formación presencial y una formación online?

- ¿Cómo quiero organizar el curso en cuanto a flexibilidad, seguimiento, actividades?

- ¿Cómo accederán los alumnos a las sesiones del curso?

- ¿Cómo puedo conocer los resultados del aprendizaje? 


\section{LA FORMACIÓN COMO HERRAMIENTA DE PREVENCIÓN EN ENFERMERÍA}

\subsection{INTRODUCCIÓN}

Como ya se ha visto en los apartados anteriores, la formación en prevención de riesgos laborales es necesaria para disminuir la accidentabilidad laboral y para que los trabajadores sean capaces desarrollar su labor de manera saludable.

Un estudio realizado en diferentes países de la Unión europea, incluido España, define los diferentes perfiles formativos de los empleados públicos, así como sus necesidades formativas en materia de prevención. Este estudio se publicó en el año 2000 y entre los resultados podemos ver que el $67,9 \%$ de los participantes afirma no haber recibido formación en prevención de riesgos laborales. Las necesidades de formación detectadas hacen referencia tanto a la formación sobre temas generales, es decir, conceptos básicos de prevención, como a temas más específicos. El $98 \%$ de los trabajadores públicos españoles declaran que es necesaria una mayor formación en cuanto a temas generales de prevención de riesgos, y además, demandan una mayor formación en temas más específicos como el estrés laboral, la organización del trabajo, los factores psicosociales, etc. (44). A pesar de que estos datos pueden resultar demasiado negativos, hay que resaltar que aunque la formación en prevención de riesgos a nivel de la Administración Pública es deficiente, el sector de la sanidad es el que mayor formación de este tipo ha recibido según este estudio, aunque sigue siendo insuficiente según los datos expuestos.

En un informe más reciente realizado también por el INSHT en 2011 (45) sobre las necesidades formativas respecto a la prevención de riesgos laborales, podemos observar que la formación en este sentido no ha mejorado lo suficiente, encontrando deficiencias que es necesario subsanar. En este informe detectamos que los participantes (ya sean profesores, estudiantes, técnicos o empresas y administración) destacan la baja calidad de la formación en prevención de riesgos laborales. Los principales argumentos en los que se apoyan son que la formación suele ser muy diversa y con conceptos muy genéricos, así como demasiado teórica. También afirman que la formación universitaria no se adecua a las necesidades reales de la empresa. Este último punto ya se ha comentado cuando se hace referencia a los alumnos de prácticas de enfermería, los cuales reciben poca formación sobre prevención de riesgos laborales durante su formación 
universitaria, lo cual aumenta la probabilidad de que sufran algún tipo de accidente cuando se incorporan al mundo laboral. A este hecho podemos añadir que la formación en PRL que se imparte en los hospitales, en la mayoría de los casos suele ser de corta duración, formando a los trabajadores únicamente cuando estos comienzan su actividad en estos centros y que además, los alumnos de prácticas no suelen recibir esta formación ya que su estancia en los hospitales no es de larga duración y tampoco son considerados profesionales del centro. Sin embargo, un estudio sobre la accidentabilidad de los estudiantes de enfermería señala que ésta es muy elevada detectándose importantes deficiencias de seguridad (46). Por lo tanto, es necesario incluir a los estudiantes de enfermería en los programas formativos de prevención de riesgos laborales que van dirigidos al personal sanitario.

Por último, según la Encuesta Nacional de Gestión de Riesgos Laborales en las Empresas de 2015, en nuestro país la formación en prevención de riesgos laborales se sitúa por delante que en el resto de países europeos, sin embargo, si diferenciamos la formación recibida en los diferentes sectores de actividad vemos que en la sanidad (junto con educación y servicios sociales) es donde se observan los porcentajes más bajos de este tipo de formación. En cuanto a la formación en materia de prevención de los mandos superiores e intermedios, este informe nos revela que es en la administración pública donde encontramos el porcentaje más bajo en cuanto a la formación en riesgos laborales (43).

El sector sanitario engloba diferentes colectivos de profesionales, cada uno de ellos con determinadas tareas, muchas de las cuales se compaginan. En nuestro caso, el plan de formación que se ha diseñado va orientado al colectivo de enfermería, dentro del cual se incluyen a los alumnos de prácticas que cada año rotan por los diferentes servicios clínicos hospitalarios. Se ha tratado de realizar un plan de formación que permita una formación continuada durante todo el año, que compagine la formación teórica y la práctica de los participantes y que, sobre todo, englobe a los profesionales de enfermería y a los alumnos de prácticas.

Para diseñar el plan de formación que se presenta en este trabajo seguimos la iniciativa propuesta por el Instituto Nacional de Seguridad e Higiene en el Trabajo, que es una campaña cuyo principal objetivo es la promoción de la salud. La campaña está diseñada para realizarla durante los doce meses del año y cuenta con cuatro fases destinadas a realizarse durante las cuatro semanas de cada mes. 
La primera semana se centra en la exposición, en el lugar de trabajo, de carteles sobre un determinado tema, de manera que se consiga la atención de los trabajadores sobre dicho tema. La segunda semana esos mismos carteles irían acompañados de texto, por lo tanto, por una lado resolveríamos las dudas de los trabajadores (y seguiríamos captando su atención) y por otro estaríamos introduciendo el tema de debate, que se realizaría la tercera semana. En el debate, todos los participantes podrían compartir opiniones sobre el tema en cuestión, así como experiencias propias, mecanismos de resolución de incidentes, dudas sobre el tema tratado, etc. Finalmente, la cuarta semana estaría destinada a repartir información, en forma de folletos, sobre el tema tratado ese mes.

La realización de un plan de formación anual, dividido en los 12 meses del año, facilita que las nuevas incorporaciones a la empresa puedan iniciar y continuar el plan organizado.

\subsection{OBJETIVOS}

- Acercar al colectivo de enfermería (profesionales y alumnos de prácticas) a la prevención de riesgos psicosociales.

- Realizar una formación continuada, uniendo la teoría y la práctica.

- Fomentar la participación de todos los profesionales para que se sientan integrados en la prevención de riesgos.

- Formar e informar a los trabajadores en materia de prevención de riesgos laborales, dándoles a conocer los riesgos asociados a su actividad diaria y las principales medidas preventivas que deben conocer para evitarlos y/o afrontarlos.

- Enfocar la prevención de riesgos laborales desde una perspectiva distinta para que los trabajadores la integren en su día a día y dejen de verla como "el típico curso de formación que haces cuando te dan un contrato". 


\subsection{ESTRUCTURA DEL PLAN DE FORMACIÓN}

El plan de formación que se propone se divide en siete módulos, que quedarían distribuidos de la siguiente forma:

\begin{tabular}{lc}
\hline Mes & Temática \\
\hline ENERO & Prevención de Riesgos Laborales \\
\hline FEBRERO & Riesgos Biológicos \\
\hline MARZO & Riesgos Biológicos \\
\hline ABRIL & Riesgos Químicos \\
MAYO & Riesgos Físicos \\
JUNIO & Riesgos Ergonómicos \\
JULIO & Prevención de Riesgos Laborales \\
AGOSTO & Prevención de Riesgos Laborales \\
SEPTIEMBRE & Riesgos Psicosociales \\
OCTOBRE & Riesgos Psicosociales \\
\hline NOVIEMBRE & Riesgos Psicosociales \\
DICIEMBRE & Repaso \\
\hline
\end{tabular}

Tabla 1. Estructura del Plan de Formación.

El primer mes, enero, lo utilizaríamos para hacer una introducción a modo general de la Prevención de Riesgos Laborales en Enfermería. En esta sesión también se realizaría un test inicial para ver los conocimientos base de los participantes.

Los meses de julio y agosto, que suelen ser los meses en los que más incorporaciones reciben los centros sanitarios debido a las vacaciones de los trabajadores, se dedicarían a realizar el mismo curso que en el mes de enero, de forma que los nuevos trabajadores tengan acceso a esta formación básica.

En el mes de diciembre se haría un repaso de la materia impartida con el fin de que los participantes recuerden los principios básicos de la prevención en todas sus especialidades, y se realizaría un test para evaluar los conocimientos adquiridos. Este test nos serviría para modificar o adaptar el plan de formación en base a las posibles carencias que se encuentren.

A continuación especificamos los temas que se darían en las sesiones formativas presenciales, correspondientes a la tercera semana de cada mes. En el folleto informativo que se repartirá la cuarta semana de cada mes irán recogidas las ideas principales de cada sesión formativa. La primera y la segunda semana de cada mes se harán diseños de carteles con el tema que se 
desarrollará en estas sesiones, para introducirlo a modo general y que los trabajadores comiencen a comentarlo.

ENERO (Julio y agosto)

Durante este mes el tema principal sería la prevención de riesgos laborales en el personal de enfermería. Se trata de dar una visión general de la prevención para el desarrollo laboral diario de estos trabajadores, por lo tanto, esta sesión se repetiría los meses de julio y agosto.

Es importante aprovechar esta sesión para presentar los datos de la VII Encuesta Nacional de Condiciones de Trabajo así como los datos de accidentabilidad referidos a la profesión de enfermería. De esta manera lograríamos concienciar a los trabajadores de la importancia que tiene la prevención de riesgos en su día a día.

- Exposición de los resultados de la VII Encuesta Nacional de Condiciones Laborales y datos de accidentabilidad en el sector sanitario.

- Realización de un test para saber los conocimientos de los participantes en cuanto a prevención de riesgos laborales.

- Medidas generales de Prevención de Riesgos Laborales a nivel biológico, químico, físico, ergonómico y psicosocial. Explicar la necesidad de utilizar siempre los equipos de protección individual y de no asumir riesgos de manera deliberada.

- Informar sobre la importancia que tiene la comunicación de riesgos laborales para la mejora de la prevención.

\section{FEBRERO}

En febrero se inicia el módulo de Riesgos Biológicos, que durará dos meses. En este primer mes se hablará:

- Proyecto EPINETAC. Informar a los trabajadores de la existencia de este proyecto a nivel nacional y de los datos que a partir de él se extraen.

- Descripción de los principales riesgos biológicos a los que se exponen los trabajadores y de las medidas de protección que deben adoptar. 
MARZO

Continuando con el módulo de Riesgos Biológicos, este mes estará dedicado a:

- Explicar el protocolo de exposición accidental a agentes biológicos.

- Introducir el tema de la vacunación y de la necesidad de que todos los trabajadores se realicen los reconocimientos médicos anuales que lleva a cabo el Servicio de Prevención.

- Residuos sanitarios

ABRIL

Durante el mes de abril se tratarán los Riesgos Químicos. Es importante que los trabajadores conozcan a qué tipo de sustancias están expuestos y sepan de este modo reconocerlas.

- Identificar las sustancias químicas con las que los participantes trabajan a diario. Exponer los riesgos y las medidas de prevención.

- Dar a conocer el diferente etiquetado de estas sustancias y las fichas de seguridad para que los trabajadores sepan interpretarlas.

MAYO

Este mes se centrará en los Riesgos Físicos. Ya se ha comentado que no todos los trabajadores se enfrentan a este tipo de riesgos, pero es necesario mencionarlos porque puede ser que en algún momento de su vida laboral lo hagan.

- Describir los riesgos físicos y los daños a la salud que producen.

- Asociar los distintos tipos de radiaciones a los diferentes servicios clínicos propios de un hospital y a los distintos equipos de trabajo.

- Enumerar las medidas de prevención que es necesario adoptar.

JUNIO

Durante este mes el tema será los Riesgos Ergonómicos. De manera tradicional en la prevención de riesgos se ha dado mayor importancia a los riesgos biológicos y a los riesgos químicos, por esta razón es importante familiarizar a los profesionales con los riesgos ergonómicos, ya que durante su labor diaria hacen movimientos y esfuerzos, de los que a lo mejor no son conscientes 
la mayoría de las veces, y que pueden ocasionar daños a su salud. De igual manera, la incorporación de los ordenadores a la rutina de trabajo diario y la informatización de las historias clínicas, son motivo de que los trabajadores pasen mucho tiempo sentados expuestos a las pantallas de visualización de datos y adoptando posturas que no siempre son correctas.

- Descripción de los riesgos ergonómicos y los daños a la salud que producen.

- Enseñar las diferentes técnicas de movilización de enfermos.

\section{SEPTIEMBRE}

En este mes se da inicio al módulo de Riesgos Psicosociales. A este módulo le dedicamos tres meses porque, al igual que ocurría con los riesgos ergonómicos, la mayoría de los profesionales sanitarios no están muy familiarizados con este tipo de riesgos. Durante este primer mes:

- Se expondrán los riesgos psicosociales y sus principales causas.

\section{OCTUBRE}

Siguiendo con el módulo de Riesgos Psicosociales, este mes se profundizará un poco más en ellos.

- Explicar qué es el estrés laboral, sus principales causas y los síntomas que nos permitan reconocerlo.

- Introducir el Síndrome de estar Quemado en el Trabajo o burnout, y la sintomatología asociada para que sepan reconocerlo.

\section{NOVIEMBRE}

Para finalizar el módulo de Riesgos Psicosociales se enseñará a los participantes las principales estrategias de afrontamiento de los riesgos psicosociales. Este curso se podría orientar en modo taller para que los alumnos puedan poner en práctica las estrategias que se les enseñan.

- Explicar qué es la Psicología Positiva

- Explicar estrategias para mejorar las habilidades de comunicación, mejorar la autoeficacia, hablar sobre el liderazgo y enseñar a ser un buen líder. 


\section{DICIEMBRE}

Como ya se ha comentado, durante este mes se hará un repaso de la temática impartida durante todo el año, resaltando los temas principales de cada uno de los módulos.

Además, se realizará un test de conocimientos para ver cómo han evolucionado los alumnos desde el inicio del plan de formación. 


\section{MÓDULO 1. INTRODUCCIÓN A LA PREVENCIÓN DE RIESGOS LABORALES}

\begin{tabular}{|c|c|}
\hline \multicolumn{2}{|c|}{$\begin{array}{c}\text { ENERO / JULIO Y AGOSTO } \\
\text { INTRODUCCIÓN A LA PREVENCIÓN DE RIESGOS LABORALES }\end{array}$} \\
\hline 10 SEMANA & $\begin{array}{l}\text { Exposición de dibujos que representen diferentes } \\
\text { situaciones de riesgo laboral. }\end{array}$ \\
\hline 2a SEMANA & $\begin{array}{l}\text { Acompañar las imágenes expuestas la primera semana con } \\
\text { textos que hagan preguntas sobre qué medidas de } \\
\text { prevención adoptarías en cada una de las situaciones } \\
\text { expuestas. }\end{array}$ \\
\hline 3a SEMANA & $\begin{array}{l}\text { Charla informativa sobre los siguientes aspectos: } \\
\text { - Exposición de los resultados de la VII Encuesta Nacional } \\
\text { de Condiciones Laborales y datos de accidentabilidad en el } \\
\text { sector sanitario. } \\
\text { - Realización de un test para saber los conocimientos de } \\
\text { los participantes en cuanto a prevención de riesgos } \\
\text { laborales. } \\
\text { - Medidas generales de Prevención de Riesgos Laborales a } \\
\text { nivel biológico, químico, físico, ergonómico y psicosocial. } \\
\text { Explicar la necesidad de utilizar siempre los equipos de } \\
\text { protección individual y de no asumir riesgos de manera } \\
\text { deliberada. } \\
\text { - Informar sobre la importancia que tiene la comunicación } \\
\text { de riesgos laborales para la mejora de la prevención. } \\
\text { - Test de evaluación inicial. }\end{array}$ \\
\hline 4a SEMANA & $\begin{array}{l}\text { Entrega de documentación en la que se resuman los } \\
\text { principales aspectos explicados durante la } 3 \underline{a} \text { semana. }\end{array}$ \\
\hline
\end{tabular}




\section{MÓDULO 2. RIESGOS BIOLÓGICOS}

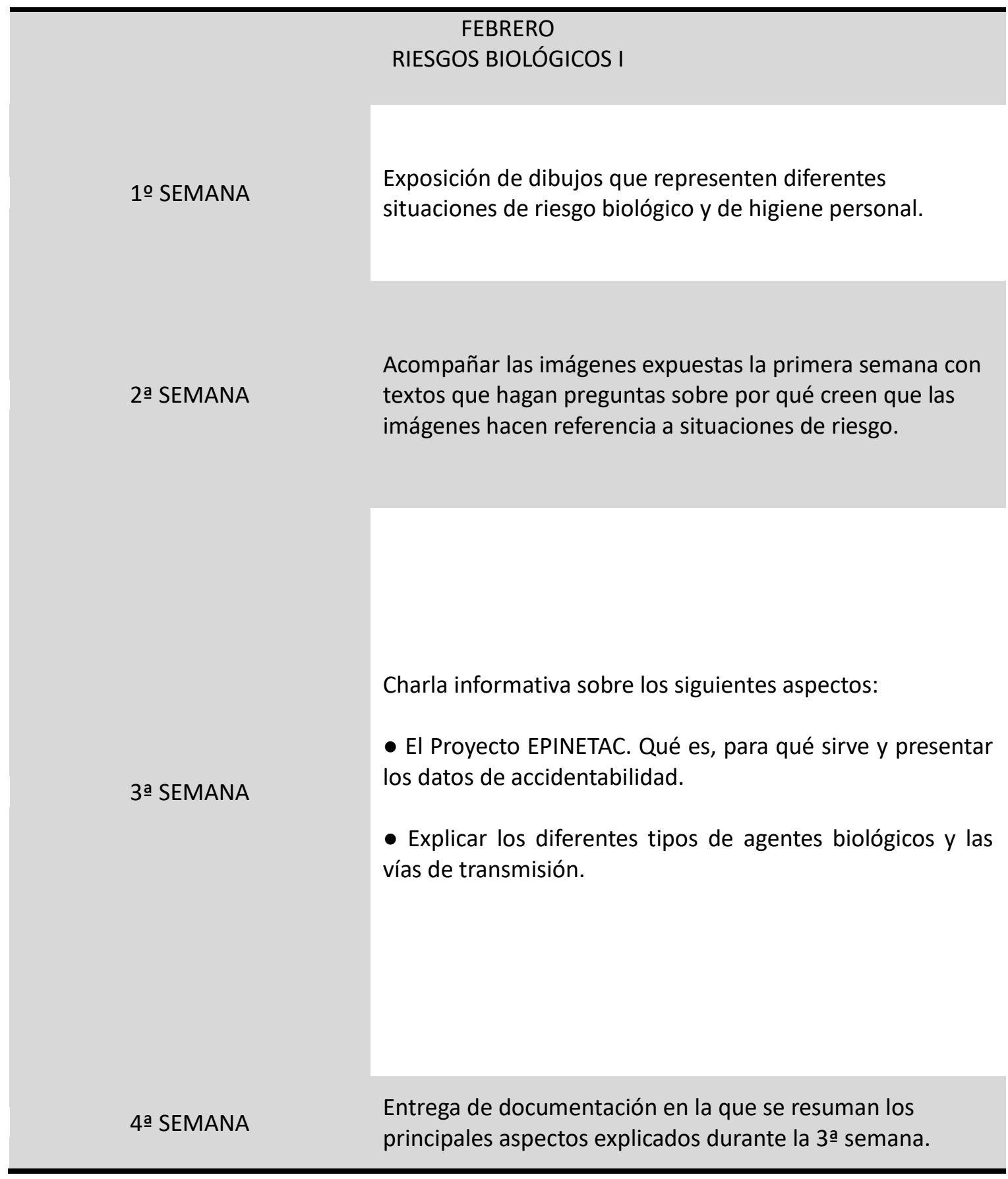




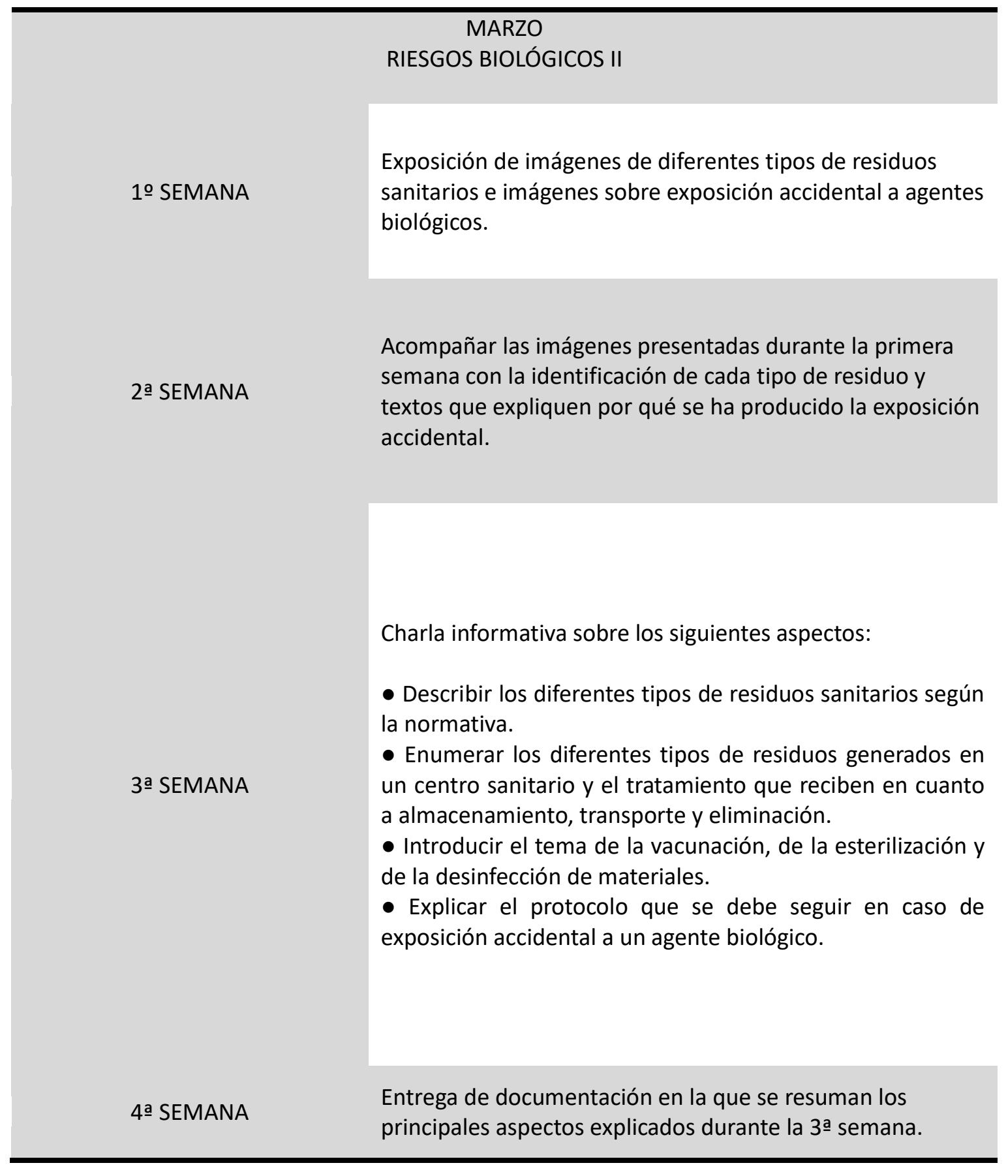


MÓDULO 3. RIESGOS QUÍMICOS

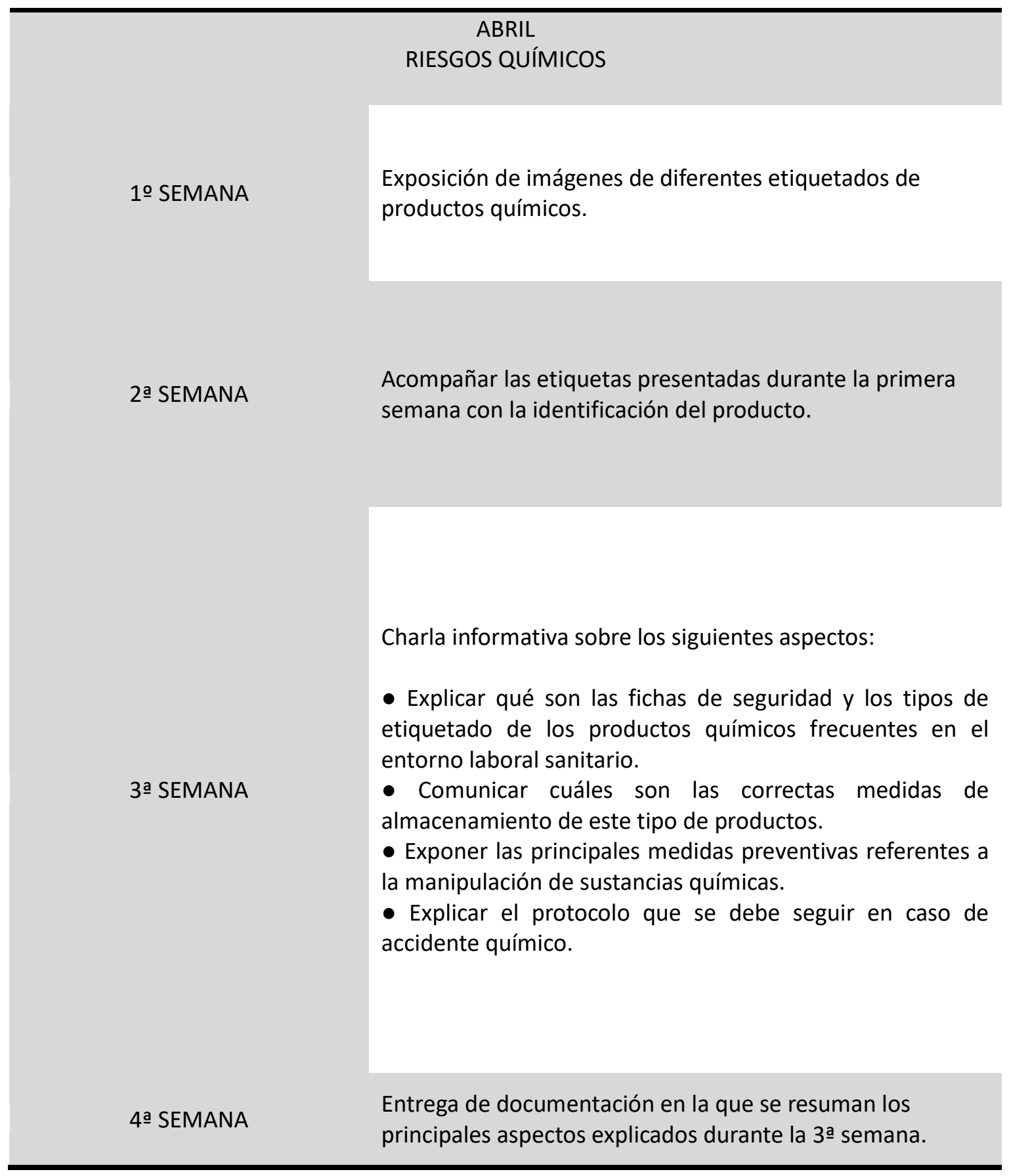


MÓDULO 4. RIESGOS FísICOS

\begin{tabular}{|c|c|}
\hline & $\begin{array}{c}\text { MAYO } \\
\text { RIESGOS FÍSICOS }\end{array}$ \\
\hline 1ㅇ SEMANA & $\begin{array}{l}\text { Exposición de imágenes de los diferentes equipos sanitarios } \\
\text { que emiten radiaciones y de las lesiones o efectos en las } \\
\text { personas que estos producen. }\end{array}$ \\
\hline 2a SEMANA & $\begin{array}{l}\text { Acompañar las imágenes con el tipo de radiación que es y } \\
\text { especificar las lesiones y efectos. }\end{array}$ \\
\hline \multirow{3}{*}{ 3a SEMANA } & $\begin{array}{l}\text { Charla informativa sobre los siguientes aspectos: } \\
\text { - Explicar cuáles son los diferentes tipos de radiación } \\
\text { existentes y sus efectos para la salud. }\end{array}$ \\
\hline & $\begin{array}{l}\text { - Enseñarles a discriminar entre las diferentes radiaciones a } \\
\text { las que se exponen en función del tipo de trabajo que } \\
\text { realizan. }\end{array}$ \\
\hline & $\begin{array}{l}\text { - Conocer las medidas de prevención necesarias para evitar } \\
\text { posibles daños a su salud y notificar aquellas medidas que } \\
\text { crean que no se cumplen. }\end{array}$ \\
\hline 4a SEMANA & $\begin{array}{l}\text { Entrega de documentación en la que se resuman los } \\
\text { principales aspectos explicados durante la } 3 \text { a semana. }\end{array}$ \\
\hline
\end{tabular}


MÓDULO 5. RIESGOS ERGONÓMICOS

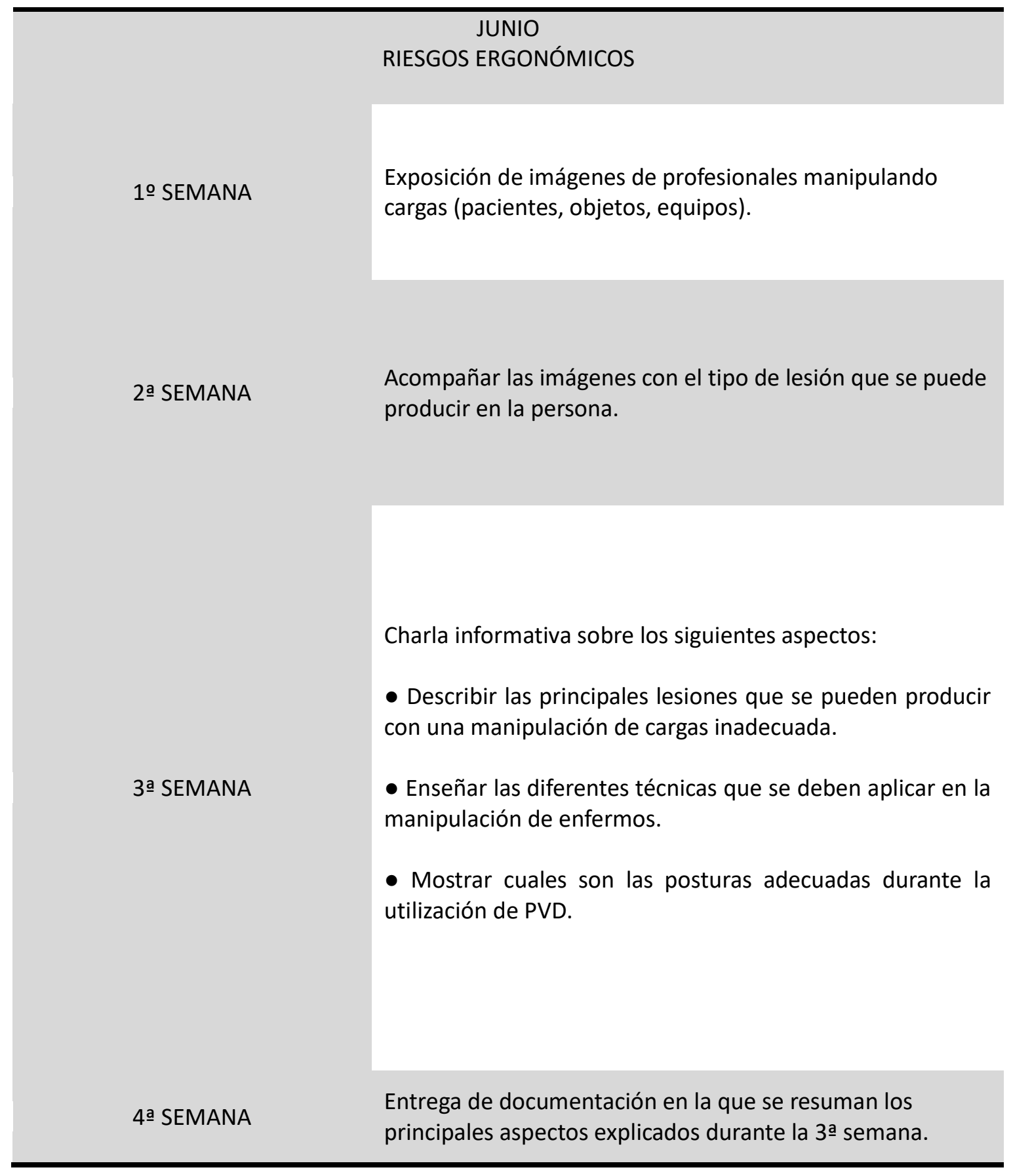


MÓDULO 6. RIESGOS PSICOSOCIALES

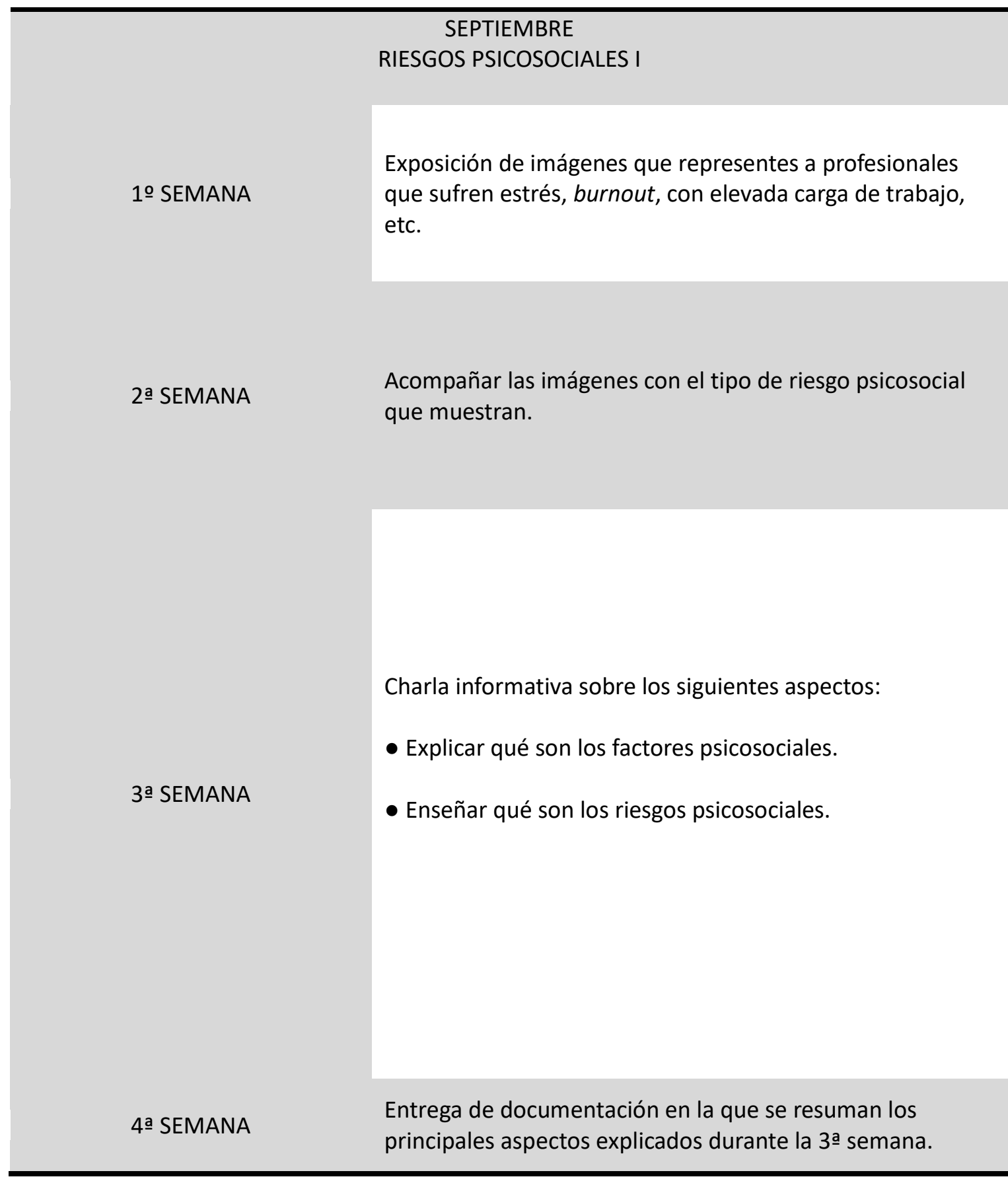




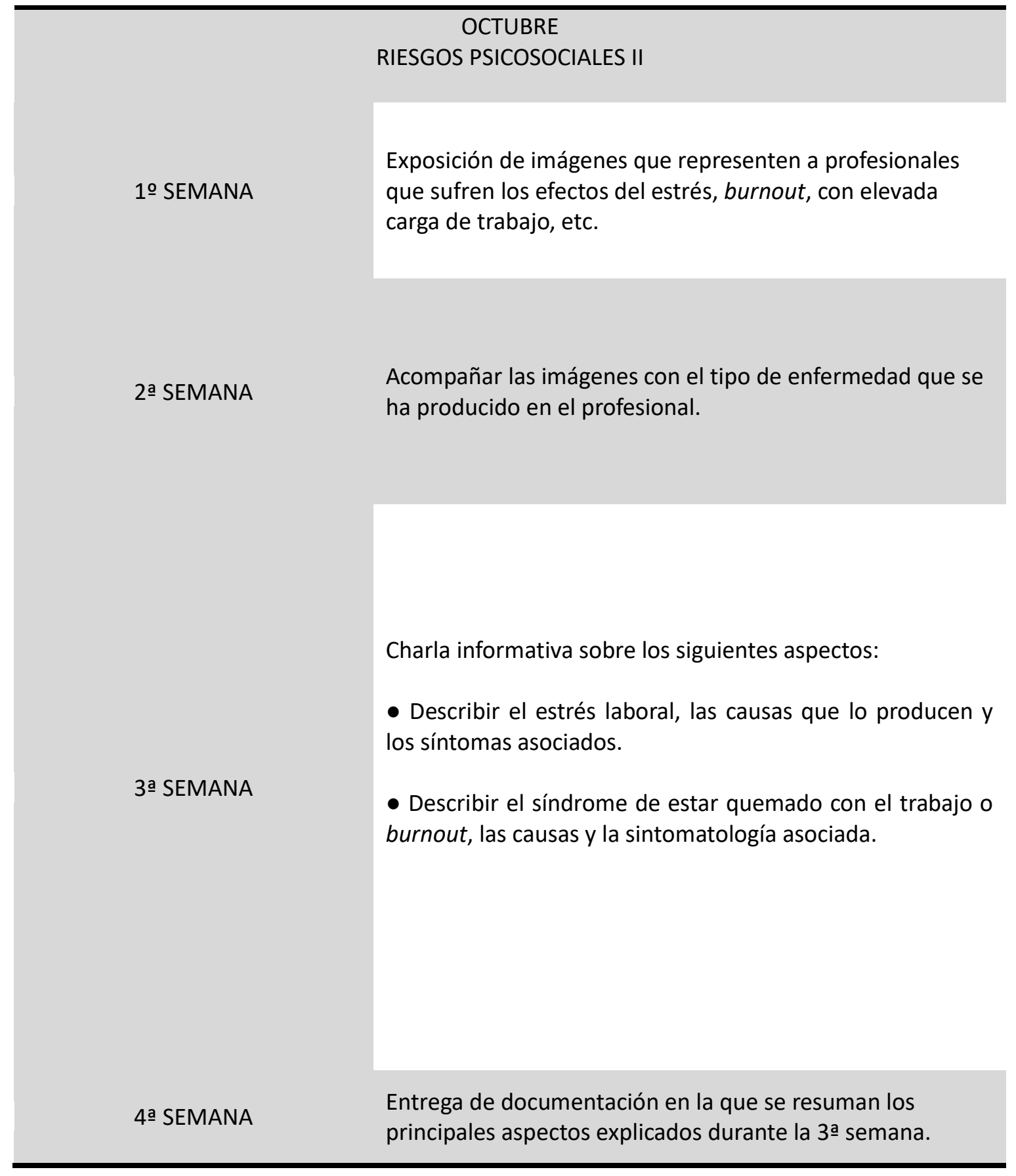




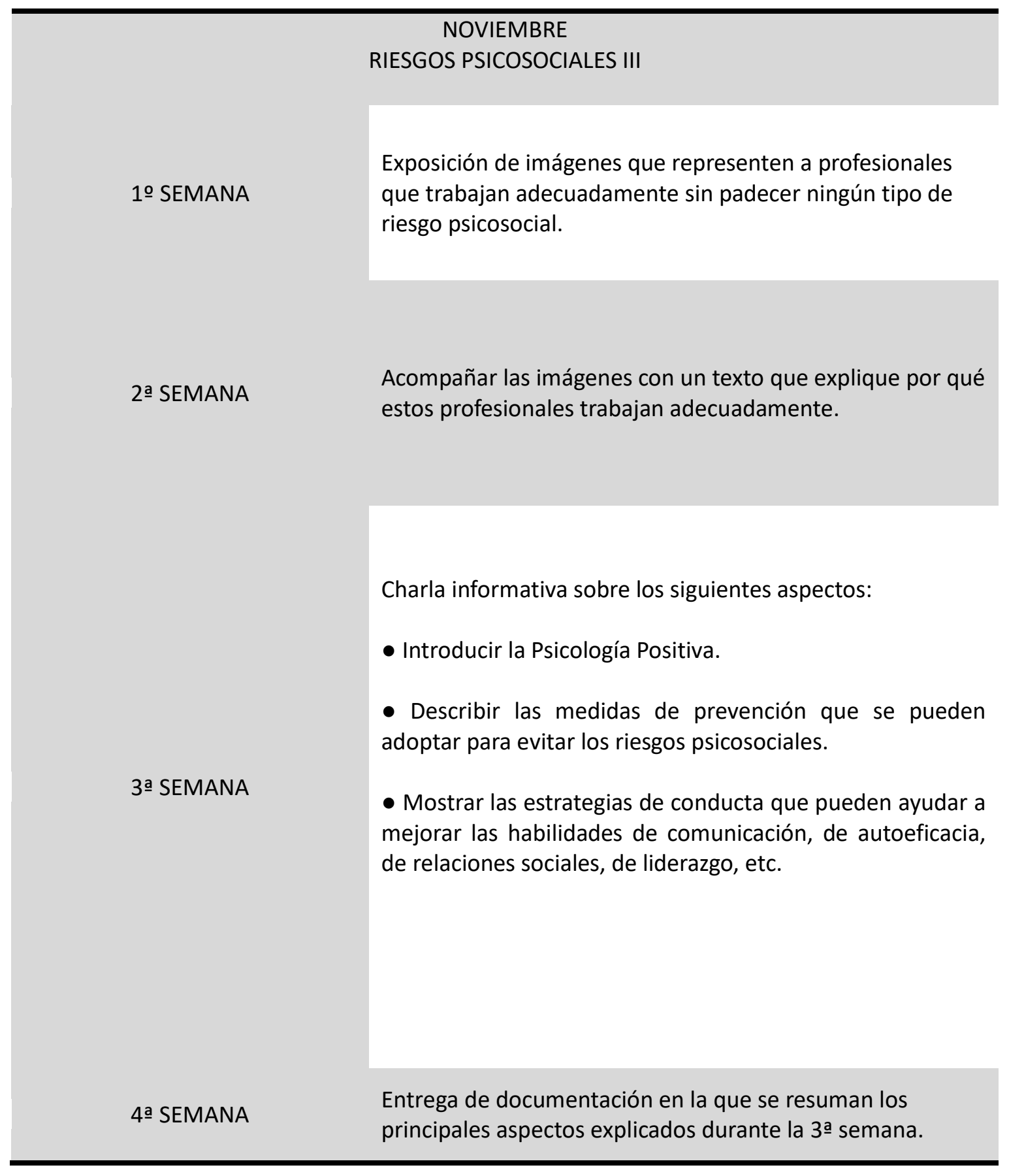




\section{MÓDULO 7. REPASO Y TEST FINAL DE EVALUACIÓN}

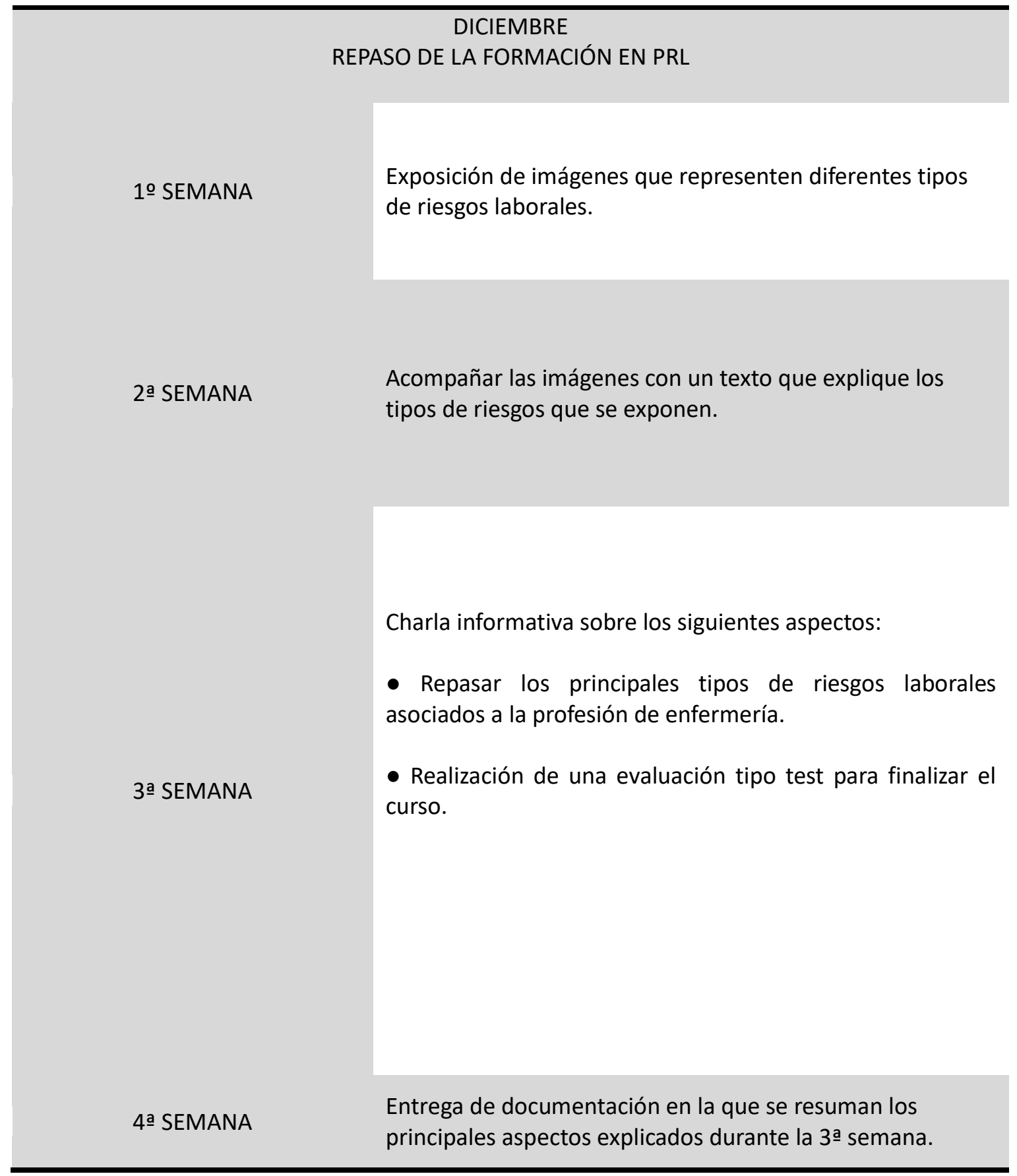




\section{ESTRATEGIA DE COMUNICACIÓN DE RIESGOS}

Al igual que el plan de formación, la estrategia de comunicación de riesgos va dirigida tanto al colectivo de enfermería como a los alumnos de prácticas que realizan dichas prácticas en los hospitales.

La formación que estos alumnos reciben en la universidad sobre prevención de riesgos laborales no suele ser muy exhaustiva, por lo tanto, cuando se enfrentan por primera vez al ambiente laboral de un hospital se pueden producir accidentes laborales fácilmente.

Sin embargo, a este hecho podemos sacarle ventaja. Al no estar lo suficientemente formados, si nosotros les ofrecemos esta formación, nos pueden ayudar a localizar los riesgos que no tenemos controlados, y además, al no tener experiencia profesional no tienen adquiridos comportamientos de asunción de riesgos, y para ellos será más fácil detectar necesidades y precariedades.

Es necesario concienciar a todos los trabajadores de la importancia que tiene la comunicación de riesgos para la mejora continua de la prevención de riesgos laborales, pero también es necesario hacerlo con estos estudiantes, que por las características de las prácticas que realizan, suelen rotar por diferentes servicios clínicos y realizar todo tipo de prácticas clínicas.

La propuesta es hacer partícipes a los estudiantes de prácticas de lo valiosos que son para el Servicio de Prevención de Riesgos del hospital. Informarles de por qué es tan importante la comunicación de riesgos y presentarles el documento que deben rellenar para informar cualquier deficiencia que detecten (ANEXO 1). Para ello, cuando los alumnos inicien las prácticas profesionales se les debería reunir e informarles del plan de prevención de riesgos laborales y de la estrategia de comunicación de los riesgos detectados. Sería conveniente seleccionar a un alumno para que sea el portavoz a la hora de comunicar los riesgos que cada uno de ellos detecte, de esta forma centralizaríamos las vías de comunicación en uno de ellos que sería el que establecería contacto con el Servicio de Prevención.

También es interesante realizar reuniones periódicas (en función de la frecuencia de comunicación de riesgos) para informar al personal de enfermería y a los alumnos de los riesgos que se han ido detectando y de las medidas de corrección que se han adoptado. De esta forma, 
tanto unos como otros verán que el esfuerzo que hacen en relación a la comunicación de riesgos tiene una utilidad práctica y que el Servicio de Prevención tiene en cuenta sus aportaciones, algo sin duda que les recompensará. 


\section{CONCLUSIONES}

Con el trabajo que se presenta se ha intentado elaborar un Plan de Formación que se pueda utilizar como herramienta para poder prevenir los riesgos laborales asociados a la profesión de enfermería.

Las principales conclusiones a las que se ha llegado son:

- Teniendo en cuenta los datos de la VII Encuesta Nacional de Condiciones de Trabajo relativos a la exposición a los diferentes tipos de riesgos laborales (biológicos, químicos, ergonómicos y psicosociales) de las profesiones sanitarias, un plan de formación dirigido específicamente a los riesgos que afectan a este colectivo debería causar un impacto positivo en las condiciones de trabajo.

- Una mayor y mejor formación de los profesionales sanitarios debe influir en la accidentabilidad del sector de manera positiva, la cual, según el Informe Anual de Accidentes en España del INSHT de 2016, ha aumentado en los últimos años analizados.

- La implantación de un plan de formación durante todo el año permitirá que la prevención de riesgos se vea desde otra perspectiva y se integre en el trabajo diario de los profesionales, que a su vez, se sentirán más protegidos. Además, la creación de una estrategia de comunicación de riesgos a nivel de profesionales y alumnos de prácticas favorecerá la creación de un entorno laboral saludable, ya que la posibilidad de comunicar los riesgos nos permitirá subsanarlos, y entre todos mejorar la salud laboral.

- Dividiendo nuestro plan de formación en los doce meses del año y utilizando una estrategia más visual y efectiva, estamos participando en la iniciativa del Instituto Nacional de Seguridad e Higiene en el Trabajo de Promoción de la Salud en el Trabajo y ayudará a mejorar los datos extraídos de la Encuesta Nacional de Gestión de Riesgos Laborales en la Empresa de 2015, según la cual existe una deficiencia en cuanto a formación preventiva en las administraciones públicas en general. 


\section{REFERENCIAS BIBLIOGRÁFICAS}

1. Murillo García B. Características del sector hospitalario. En: Il Jornada PRL y Empresa: Nuevas actuaciones preventivas en el sector hospitalario y sociosanitario: 19 de mayo de 2016, Barcelona. Universitat Oberta de Catalunya.

2. Gómiz León E. El profesional de enfermería, por la gestión del riesgo, hacia la seguridad del paciente. Rev. Soc. Esp Enferm Nefrol 2007; 10 (1): 63/64).

3. Comisión de las Comunidades Europeas. Cómo adaptarse a los cambios en la sociedad y en el mundo del trabajo: una nueva estrategia comunitaria de salud y seguridad (2002-2006). Bruselas; 2002.

4. Comisión de las Comunidades Europeas. Cómo adaptarse a los cambios en la sociedad y en el mundo del trabajo: una nueva estrategia comunitaria de salud y seguridad (2002-2006). Bruselas; 2002.

5. Cano Galán Y. La formación en PRL: su configuración como deber de los trabajadores [Internet]. Revista del Ministerio de Trabajo y Asuntos Sociales. Consultado el 26/02/2017. Recuperado a partir de: http://www.empleo.gob.es/es/publica/pub electronicas/destacadas/revista/numeros/53/ Est08.pdf

6. Fernández-Sabinero Miguel C. El diseño de un plan de formación como estrategia de desarrollo empresarial [Internet]. Revista Complutense de Educación. 1999, vol. 10, no1: 181-242. Consultado el 26/02/2017. Recuperado a partir de: https://www.sepe.es/contenidos/empresas/formacion/plan formacion tu empresa.html

7. Instituto Nacional de Seguridad e Higiene en el Trabajo. VII Encuesta Nacional de Condiciones de Trabajo. Madrid; 2011.

8. Instituto Nacional de Seguridad e Higiene en el Trabajo. Informe anual de accidentes de trabajo en España. Madrid; 2016.

9. Secretaría de Salud Laboral. Guía básica de riesgos laborales específicos en el sector sanitario. CC.OO. Castilla y León; 2011. 
10. Instituto Nacional de Seguridad e Higiene en el Trabajo. Informe sobre el estado de la seguridad y salud laboral en España (2015). Madrid; 2016.

11. Alamillos Ortega P, Andani Cervera J, Cabrera García MA, Chirivella Cases J, Collazos Dorronsoro A, Fernández Escribano M et al. Guía de criterios de aptitud para trabajadores del ámbito sanitario. Escuela Nacional de Medicina del Trabajo. Instituto de Salud Carlos III. Ministerio de Economía y Competitividad. Madrid; 2014.

12. Hernández Calleja A; NTP 833: Agentes biológicos. Evaluación simplificada. Instituto Nacional de Seguridad e Higiene en el Trabajo; 2009.

13. Cebrián Picazo F, Fernández Requena JJ. Riesgo biológico en trabajadores sanitarios. Guía práctica para su prevención. Conselleria de Treball i Formació. Govern de les Illes Balears; 2004.

14. Secretaría de Salud Laboral. Guía básica de riesgos laborales específicos en el sector sanitario. CC.OO. Castilla y León; 2011.

15. Prescal. Prevención de riesgos laborales en sanidad [Internet]. Junta de Andalucía. Consultado el 27/03/2017. Recuperado a partir de: http://www.juntadeandalucia.es/empleo/recursos2/material didactico/comun/prevencio $\underline{\mathrm{n} \text { riesgos laborales/sanidad/cuaderno.pdf }}$

16. Martí Solé MC, Alonso Espadalé RM. NTP 372: Tratamiento de residuos sanitarios. Instituto Nacional de Seguridad e Higiene en el Trabajo. 1993.

17. Secretaría de Salud Laboral. Guía básica de riesgos laborales específicos en el sector sanitario. CC.OO. Castilla y León; 2011.

18. Nogareda Cuixart S, Alcaide Altet N, Arce Llevadías Y, Barroso Reinón S, Benito Carreras D, Carreras Valls $\mathrm{R}$ et al. Prevención de trastornos musculoesqueléticos en el sector sanitario. Buenas prácticas. Instituto Nacional de Seguridad e Higiene en el Trabajo.

19. Secretaría de Salud Laboral. Guía básica de riesgos laborales específicos en el sector sanitario. CC.OO. Castilla y León; 2011. 
20. Moreno Jiménez B, Báez León C. Factores y riesgos psicosociales: conceptualización, historia y cambios actuales. Med Segur Trab. 2011; 59 Suplemento 1:19.

21. Gil-Monte PR. Riesgos psicosociales en el trabajo y salud ocupacional. Rev. Perú Med. Exp. Salud Pública. 2012; 29 (2): 237-41.

22. Landsbergis P. ¿Qué se debe hacer para prevenir los riesgos psicosociales en el trabajo? Arch Prev Riesgos Labor. 2008; 11 (1): 36-44.

23. Salanova $\mathrm{M}$, Llorens $\mathrm{S}$. Presente y futuro de la intervención profesional en factores psicosociales. Intervención Profesional indd. 2009; 20 (59): 20-23.

24. Salanova $M$, Soler $C$. Hacia una prevención positiva de los riesgos psicosociales. Revista monográfica de Prevención de Riesgos Laborales. 2015.24-30.

25. Confederación de Empresarios de Aragón-CREA. Comunicación eficaz en PRL. Experiencias en empresas aragonesas [Internet].2014. Consultado el 27/03/2017. Recuperado a partir de: http://www.ceoearagon.es/prevencion/pdf/Comunicacion eficaz PRL.pdf

26. Jacuna Morera J, Pujol Franco L. NTP 685: La comunicación en las organizaciones. Instituto Nacional de Seguridad e Higiene en el Trabajo. 2000.

27. Huete García R. La comunicación de la prevención en la empresa [Internet].

2003. Consultado el 4/04/2017. Recuperado a partir de: http://www.rrhhmagazine.com/articulos.asp?id=255

28. Pérez Nicolás J, Solé-Gómez MD. Ganar en salud. Materiales para la comunicación interna. [Internet]. Consultado el 27/02/2017. Recuperado a partir de: (http://www.insht.es/portal/site/PromocionSalud/menuitem.084224e92eb1cbede435b19 $\underline{7280311 \mathrm{a0} / \text { ?vgnextoid=9c8d5dfb13d34310VgnVCM1000008130110aRCRD\&vgnextchann }}$ el=2f8a73b265f74310VgnVCM1000008130110aRCRD

29. Borredá A. La comunicación en el ámbito de la PRL [Internet]. Formación de Seguridad Laboral. Instituto Nacional de Seguridad e Higiene en el Trabajo. Consultado el 30/03/2017. Recuperado 
http://www.insht.es/InshtWeb/Contenidos/Instituto/Noticias/Noticias INSHT/2016/Ficher os/La\%20Comunicaci\%C3\%B3n\%20en\%20el\%20\%C3\%81mbito\%20de\%20la\%20PRL.pdf

30. Guía Docente del Grado de Enfermería (2016-2017) de la Universidad de Murcia [Internet]. Consultado el 30/03/2017. Recuperado a partir de: http://www.um.es/web/enfermeria/contenido/estudios/grados/enfermeria/2016-17/guias

31. Bestratén Belloví M, Marrón Vidal MA. NTP 561: Sistemas de gestión preventiva: procedimiento de comunicación de riesgos y propuestas de mejora. Instituto Nacional de Seguridad e Higiene en el Trabajo. 2000.

32. Marcelo C, Puente D, Ballesteros MA, Palazón A. E-learning-teleformación. Diseño, desarrollo y evaluación de la formación a través de Internet. Editorial Gestión. Madrid; 2002.

33. Brown M. Estudio de las necesidades de formación de las organizaciones en España. Santillana Formación, 2005.

34. Boronat X, Romero M. Los profesionales de la salud en Europa y Estados Unidos ante la educación presencial y el e-learning. Rev Educ Cienc Salud 2012; 9 (1): 50-52.

35. Castaño Calle R, Jenaro Río C, Flores Robaina N. Análisis DAFO de la utilidad de las plataformas de formación online para el entrenamiento en competencias de estudiantes universitarios [Internet]. EDUTEC. Revista Electrónica de Tecnología Educativa. Núm. 42/Diciembre 2012. Consultado el 7/3/2017. Recuperado a partir de: http://edutec.rediris.es/Revelec2/Revelec42/analisis DAFO utilidad plataformas formaci o onlin competencias.html).

36. Ferro C, Martínez Al, Otero MC. Ventajas del uso de las TICs en el proceso enseñanzaaprendizaje desde la óptica de los docentes universitarios españoles [Internet]. EDUTEC, Revista Electrónica de Tecnología Educativa. Núm.29/Julio 2009. Consultado el 7/03/2017. Recuperado a partir de: http://edutec.rediris.es/revelec2/revelec29/

37. Gallego Rodríguez A, Martínez Caro E. Estilos de aprendizaje y e-learning. Hacia un mayor rendimiento académico. Revista de Educación a Distancia. 2003. Núm. 7: 1-10. 
38. Marín Díaz V, Reche Urbano E, Maldonado Berea A. Ventajas e inconvenientes de la formación online. Revista Digital de Investigación en Docencia Universitaria. Dic. 2013-Año 7-Nro. 1/Lima.

39. González Arechabaleta M. Cómo desarrollar contenidos para la formación online basados en objetos de aprendizaje [Internet]. RED. Revista de Educación a Distancia, número monográfico III. 2005. Consultado el 7/3/2017. Recuperado a partir de: http://www.um.es/ead/red/M3//

40. Cabero J. "Bases pedagógicas del e-learning. Revista de Universidad y Sociedad del Conocimiento (RUSC) [Internet]. 2006. Vol. 3. № 1. UOC. Consultado el 7/3/2017. Recuperado a partir de: http://www.uoc.edu/rusc/3/1/dt/esp/cabero.pdf/

41. Bartolomé Pina A. Blended learning. Conceptos básicos. Pixel-Bit. Revista de Medios y Educación. № 23. Mayo 2004. Pp. 7-20.

42. Cabero J. Bases pedagógicas del e-learning. Revista de Universidad y Sociedad del Conocimiento (RUSC) [Internet]. 2006. Vol. 3. № 1. UOC. Consultado el 7/3/2017. Recuperado a partir de: http://www.uoc.edu/rusc/3/1/dt/esp/cabero.pdf/

43. Instituto Nacional de Seguridad e Higiene en el Trabajo. Encuesta Nacional de Gestión de Riesgos Laborales en las Empresas. ESENER-2. Madrid: INSHT; 2015. Consultado el 28/04/2017. Recuperado a partir de: http://www.insht.es/InshtWeb/Contenidos/Documentacion/FICHAS\%20DE\%20PUBLICACI ONES/EN\%20CATALOGO/OBSERVATORIO/ESENER\%20dos.pdf

44. Maestro J, Montero MA, Rivero MR. Perfiles formativos. Necesidades de formación en materia de prevención de riesgos laborales de los empleados públicos españoles. Instituto Nacional de Seguridad e Higiene en el Trabajo. 2000. Consultado el 28/04/2017. Recuperado a partir de: http://www.insht.es/InshtWeb/Contenidos/Documentacion/TextosOnline/Rev INSHT/200 $\underline{0 / 7 / \text { seccionFormTextCompl.pdf }}$

45. Gordóvil A, Costa C, Losada JL, Carrera MJ, Torres N, Farràs L, Alemany S et al. Estudio de las necesidades formativas en PRL, ante el nuevo marco docente y los cambios 
reglamentarios derivados del denominado proceso de Bolonia. INSHT. Barcelona. 2011. Consultado el 28/04/2017. Recuperado a partir de: http://www.insht.es/InshtWeb/Contenidos/Instituto/Noticias/Noticias INSHT/2011/ficher os/EstudioNecesidadesFormativasPRL1.pdf

46. Rodríguez Martín A, Novalbos Ruíz JP, Costa Alonso MJ, Zafra Mezcua JA. Accidentabilidad e incidencia de accidentes biológicos en estudiantes de enfermería. Med Clin (Barc) 2000; 115: 251-253. 


\section{ANEXO}

DOCUMENTO DE COMUNICACIÓN DE RIESGOS

Nombre

Fecha

Apellidos

Riesgo detectado

Posible solución

Servicio clínico

Trabajador

Alumno 





\section{Medicina y Salud

